Cochrane Database of Systematic Reviews

\title{
Antihypertensive withdrawal for the prevention of cognitive decline
} (Review)

Jongstra S, Harrison JK, Quinn TJ, Richard E

Jongstra S, Harrison JK, Quinn TJ, Richard E.

Antihypertensive withdrawal for the prevention of cognitive decline.

Cochrane Database of Systematic Reviews 2016, Issue 11. Art. No.: CD011971.

DOI: 10.1002/14651858.CD011971.pub2.

www.cochranelibrary.com 
TABLE OF CONTENTS

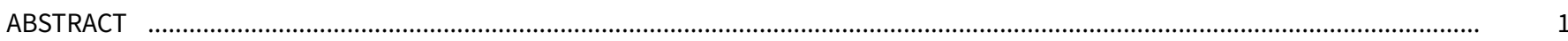

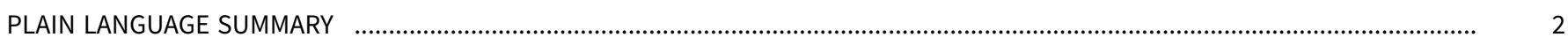

SUMMARY OF FINDINGS

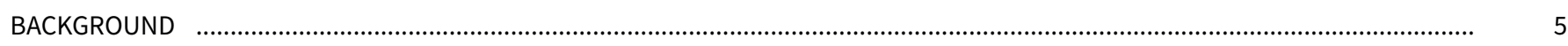

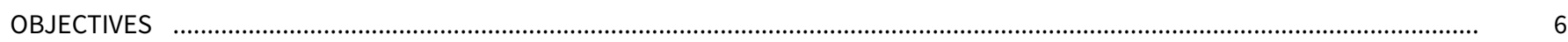

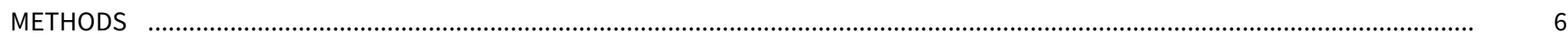

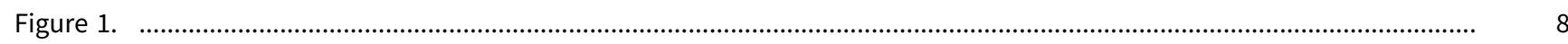

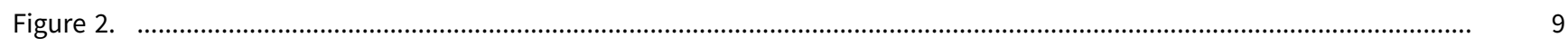

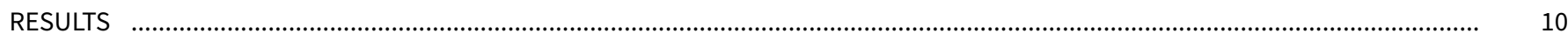

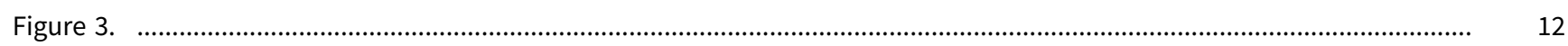

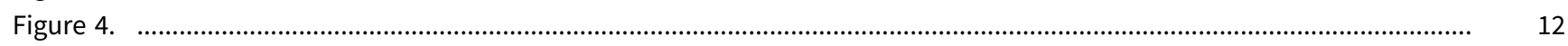

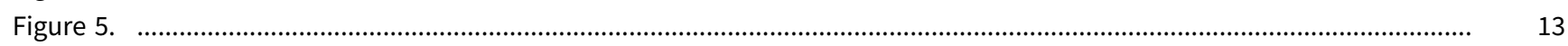

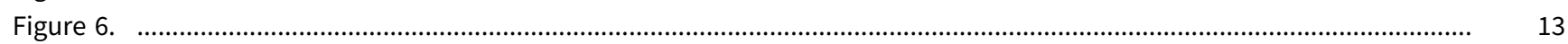

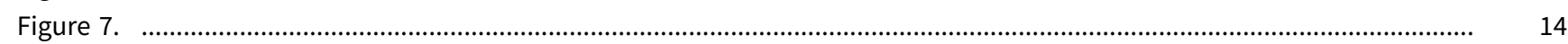

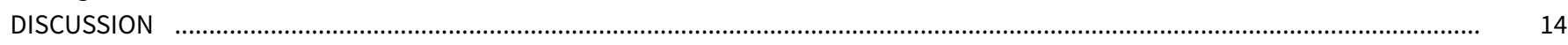

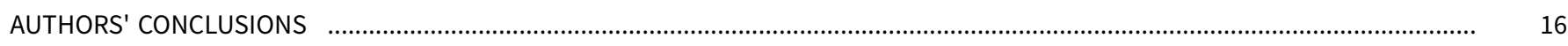

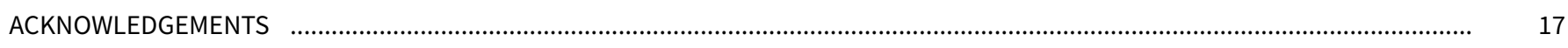

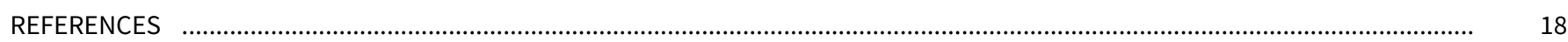

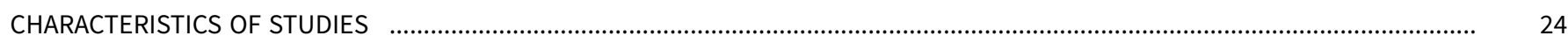

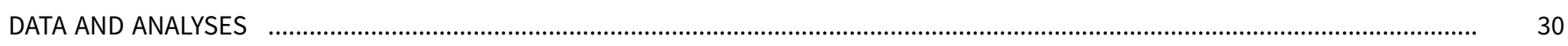

Analysis 1.1. Comparison 1 Cognitive function (at 90 days), Outcome 1 Telephone Mini-Mental State Examination score. ........ 31

Analysis 1.2. Comparison 1 Cognitive function (at 90 days), Outcome 2 Modified Telephone Interview for Cognitive Status 31 score.

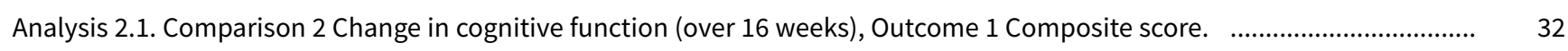

Analysis 2.2. Comparison 2 Change in cognitive function (over 16 weeks), Outcome 2 Mini-Mental State Examination score. .... 32

Analysis 2.3. Comparison 2 Change in cognitive function (over 16 weeks), Outcome 3 Stroop Interference score. ..................... 32

Analysis 2.4. Comparison 2 Change in cognitive function (over 16 weeks), Outcome 4 Trail making test score. .......................... 32

Analysis 2.5. Comparison 2 Change in cognitive function (over 16 weeks), Outcome 5 15-Word Verbal Learning Immediate Recall 32

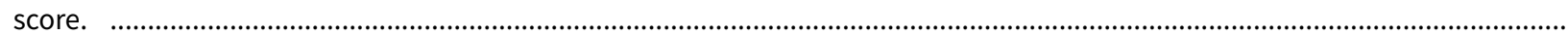

Analysis 2.6. Comparison 2 Change in cognitive function (over 16 weeks), Outcome 6 15-Word Verbal Learning Delayed Recall score.

Analysis 2.7. Comparison 2 Change in cognitive function (over 16 weeks), Outcome 7 Visual Association Test score. ................

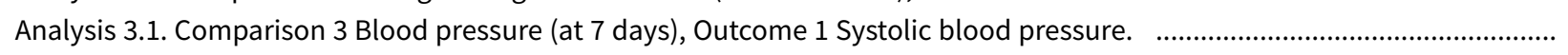

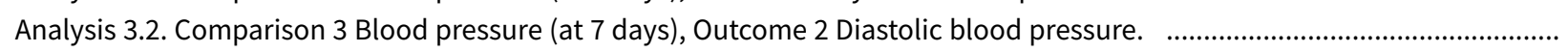

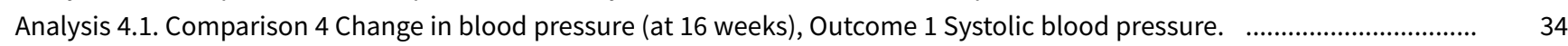

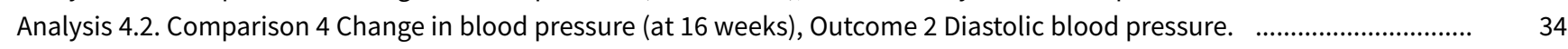

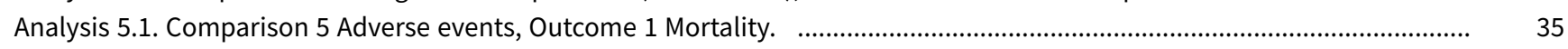

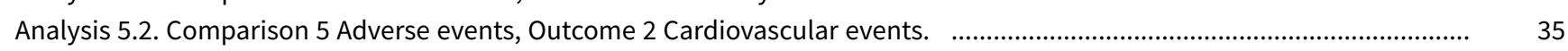

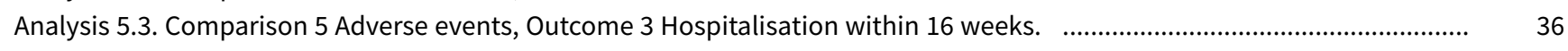

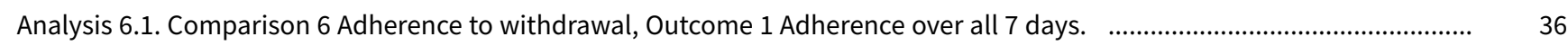

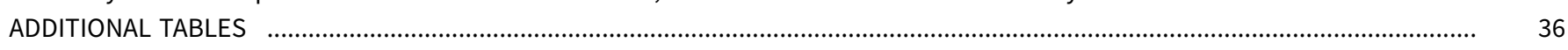

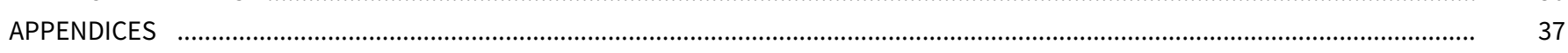

CONTRIBUTIONS OF AUTHORS

DECLARATIONS OF INTEREST

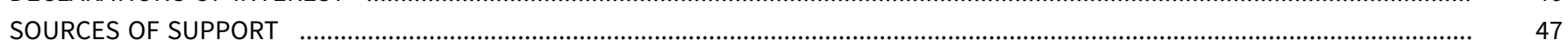

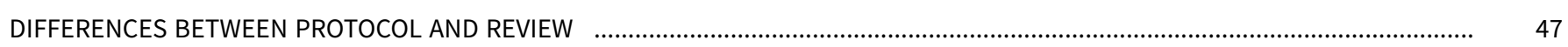

INDEX TERMS 
[Intervention Review]

\title{
Antihypertensive withdrawal for the prevention of cognitive decline
}

\author{
Susan Jongstra1 ${ }^{1}$, Jennifer K Harrison², Terry J Quinn³ ${ }^{3}$ Edo Richard4
}

1Department of Neurology, Academic Medical Centre, University of Amsterdam, Amsterdam, Netherlands. ${ }^{2}$ Centre for Cognitive Ageing and Cognitive Epidemiology and the Alzheimer Scotland Dementia Research Centre, University of Edinburgh, Edinburgh, UK. ${ }^{3 / n s t i t u t e}$ of Cardiovascular and Medical Sciences, University of Glasgow, Glasgow, UK. ${ }^{4}$ Department of Neurology, Radboud University Nijmegen Medical Center, Nijmegen, Netherlands

Contact: Terry J Quinn, Institute of Cardiovascular and Medical Sciences, University of Glasgow, Walton Building, Glasgow Royal Infirmary, Glasgow, G4 0SF, UK. Terry.Quinn@glasgow.ac.uk.

Editorial group: Cochrane Dementia and Cognitive Improvement Group.

Publication status and date: New, published in Issue 11, 2016.

Citation: Jongstra S, Harrison JK, Quinn TJ, Richard E. Antihypertensive withdrawal for the prevention of cognitive decline. Cochrane Database of Systematic Reviews 2016, Issue 11. Art. No.: CD011971. DOI: 10.1002/14651858.CD011971.pub2.

Copyright @ 2016 The Cochrane Collaboration. Published by John Wiley \& Sons, Ltd.

\section{A B S T R A C T}

\section{Background}

Clinical trials and observational data have variously shown a protective, harmful or neutral effect of antihypertensives on cognitive function. In theory, withdrawal of antihypertensives could improve cerebral perfusion and reduce or delay cognitive decline. However, it is also plausible that withdrawal of antihypertensives may have a detrimental effect on cognition through increased incidence of stroke or other vascular events.

\section{Objectives}

To assess the effects of complete withdrawal of at least one antihypertensive medication on incidence of dementia, cognitive function, blood pressure and other safety outcomes in cognitively intact and cognitive impaired adults.

\section{Search methods}

We searched ALOIS, the specialised register of the Cochrane Dementia and Cognitive Improvement Group, with additional searches conducted in MEDLINE, Embase, PsycINFO, CINAHL, LILACS, Web of Science Core Collection, ClinicalTrials.gov and the World Health Organization Portal/ICTRP on 12 December 2015. There were no language or date restrictions applied to the electronic searches, and no methodological filters were used to restrict the search.

\section{Selection criteria}

We included randomised controlled trials (RCTs) and controlled clinical trials (CCTs) provided they compared withdrawal of antihypertensive medications with continuation of the medications and included an outcome measure assessing cognitive function or a clinical diagnosis of dementia. We included studies with healthy participants, but we also included studies with participants with all grades of severity of existing dementia or cognitive impairment.

\section{Data collection and analysis}

Two review authors examined titles and abstracts of citations identified by the search for eligibility, retrieving full texts where needed to identify studies for inclusion, with any disagreement resolved by involvement of a third author. Data were extracted independently on primary and secondary outcomes. We used standard methodological procedures expected by Cochrane.

The primary outcome measures of interest were changes in global and specific cognitive function and incidence of dementia; secondary outcomes included change in systolic and diastolic blood pressure, mortality, adverse events (including cardiovascular events, hospitalisation and falls) and adherence to withdrawal. The quality of the evidence was evaluated using the GRADE approach. 


\section{Main results}

We included two RCTs investigating withdrawal of antihypertensives in 2490 participants. There was substantial clinical heterogeneity between the included studies, therefore we did not combine data for our primary outcome. Overall, the quality of included studies was high and the risk of bias was low. Neither study investigated incident dementia.

One study assessed withholding previously prescribed antihypertensive drugs for seven days following acute stroke. Cognition was assessed using telephone Mini-Mental State Examination (t-MMSE) and Telephone Interview for Cognitive Status (TICS-M) at 90 days as a secondary outcome. The t-MMSE score was a mean of 1.0 point higher in participants who withdrew antihypertensive medications compared to participants who continued them (95\% confidence interval $(\mathrm{CI}) 0.35$ to $1.65 ; 1784$ participants) and the TICS-M was a mean of 2.10 points higher ( $95 \% \mathrm{Cl} 0.69$ to $3.51 ; 1784$ participants). However, in both cases the evidence was of very low quality downgraded due to risk of bias, indirectness and evidence from a single study. The other study was community based and included participants with mild cognitive impairment. Drug withdrawal was for 16 weeks. Cognitive performance was assessed using a composite of at least five out of six cognitive tests. There was no evidence of a difference comparing participants who withdrew antihypertensive medications and participants who continued (mean difference 0.02 points, $95 \% \mathrm{Cl}-0.19$ to $0.21 ; 351$ participants). This evidence was of low quality and was downgraded due to risk of bias and evidence from single study.

In one study, the systolic blood pressure after seven days of withdrawal was $9.5 \mathrm{mmHg}$ higher in the intervention compared to the control group ( $95 \% \mathrm{Cl} 7.43$ to 11.57 ; 2095 participants) and diastolic blood pressure was $5.1 \mathrm{mmHg}$ higher (95\% $\mathrm{Cl} 3.86$ to 6.34 ; 2095 participants). This evidence was low quality, downgraded due to indirectness, because the data must be interpreted in the context of the wider study looking at glyceryl trinitrate administration or not, and evidence from a single study. In the other study, systolic blood pressure increased by $7.4 \mathrm{mmHg}$ in the withdrawal group compared to the control group $(95 \% \mathrm{Cl} 7.08$ to $7.72 ; 356$ participants) and diastolic blood pressure increased by $2.6 \mathrm{mmHg}(95 \% \mathrm{Cl} 2.42$ to $2.78 ; 356$ participants). This was moderate quality evidence, downgraded as evidence was from a single study. We combined data for mortality and cardiovascular events. There was no clear evidence that antihypertensive medication withdrawal affected adverse events, although there was a possible trend to increased cardiovascular events in the large post-stroke study (pooled mortality risk ratio $0.88,95 \% \mathrm{Cl} 0.72$ to $1.08 ; 2485$ participants; and cardiovascular events risk ratio $1.29,95 \% \mathrm{Cl} 0.96$ to 1.72 ). Certain prespecified outcomes of interest (falls, hospitalisation) were not reported.

\section{Authors' conclusions}

The effects of withdrawing antihypertensive medications on cognition or prevention of dementia are uncertain. There was a signal of a positive effect in one study looking at withdrawal after acute stroke but these results are unlikely to be generalisable to non-stroke settings and were not a primary outcome of the study. Withdrawing antihypertensive drugs was associated with increased blood pressure. It is unlikely to increase mortality at three to four months' follow-up, although there was a signal from one large study looking at withdrawal after stroke that withdrawal was associated an increase in cardiovascular events.

\section{PLAIN LANGUAGE SUMMARY}

\section{Antihypertensive withdrawal for the prevention of cognitive decline}

\section{Background}

Dementia and cognitive impairment are a global health concern which place a burden on patients and carers, and increase healthcare costs. Therefore, it is important to identify ways to prevent their occurrence. Previous research has suggested that withdrawal (stopping) of blood pressure lowering medicines might increase the blood flow to the brain and therefore prevent problems of memory and thinking in older age. In this review, we included clinical studies comparing the effects on memory and thinking of withdrawal of blood pressure lowering medicines versus continuation of these medicines.

\section{Included studies}

We found two relevant studies with 2490 participants. The two studies differed in a number of ways. One of the studies withdrew medicine for seven days immediately after a stroke, the other withdrew medicine for three months in older adults with early memory problems.

\section{Results}

The two studies did not report new cases of dementia, rather they described performance on standardised tests of memory and thinking. The older-adult study did not find a difference between the participants who stopped and participants who continued medicine. The stroke study found better test scores in participants who stopped medicine, but this must be interpreted with caution since this was measured in such a specific patient population. As expected, blood pressure rose in both studies in the groups that stopped their blood pressure lowering medicines, but there was no short-term increase in heart attacks, strokes or death.

\section{Conclusion}

At present, there is not enough evidence to prove or disprove effects of stopping blood pressure medicines on memory and thinking. 


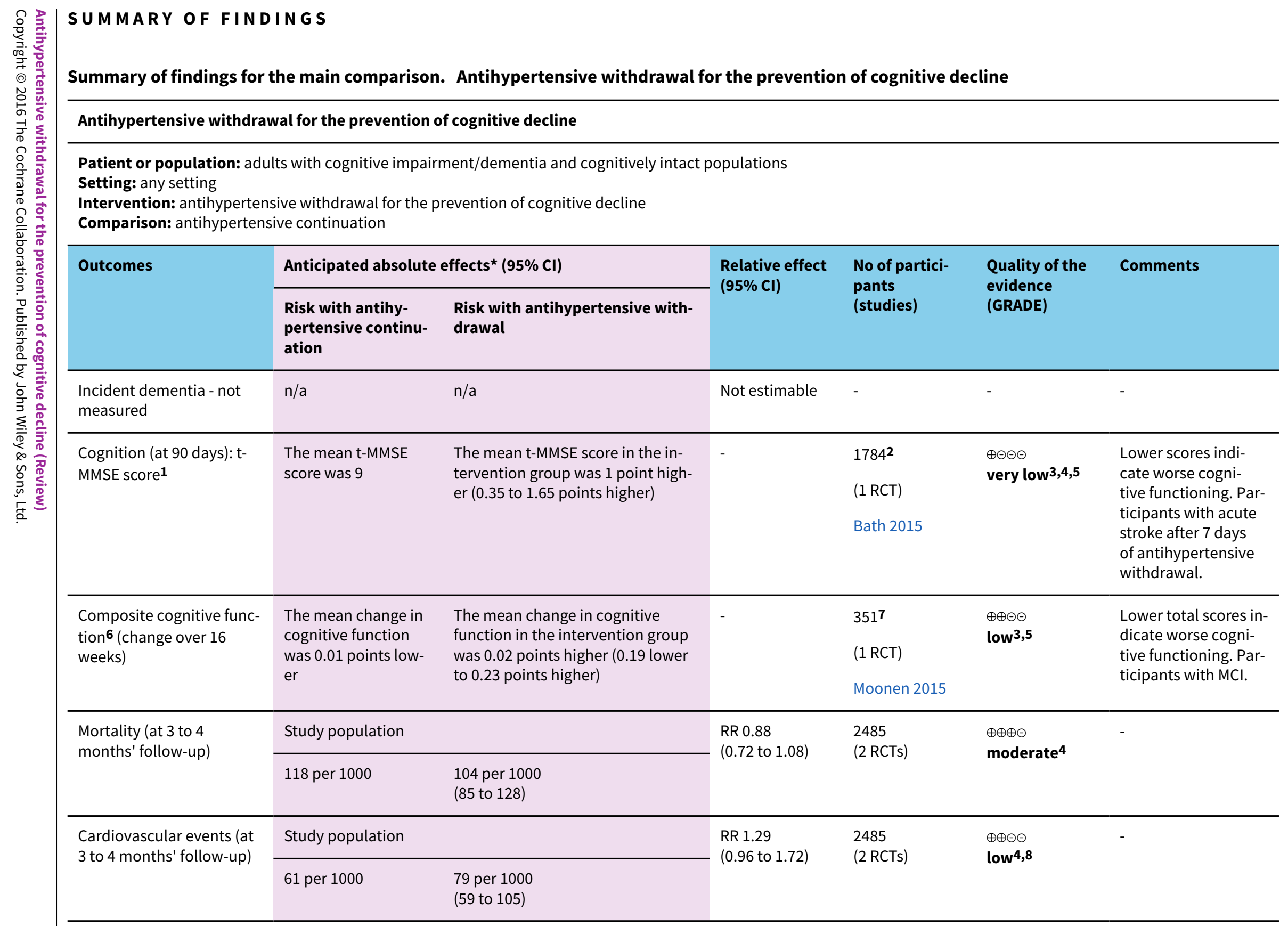

Setting: any setting 


\section{B A C K G R O U N D}

Hypertension (blood pressure above a recommended value) is a common clinical condition with a well-established causal role in cardiovascular disease (Lewington 2002). Hypertension is particularly prevalent in older age; more than half of the population over the age of 50 years, and approximately $80 \%$ of the population older than 80 years have hypertension (Chow 2013; Cohen 2011). The protective effect of antihypertensive treatment against cardiovascular events and premature mortality is well established (Law 2009; Musini 2009). The evidence to support treatment of hypertension in healthy older adults is robust (Beckett 2012). Evidence for benefit of antihypertensive therapy in frail older adults with comorbidities and geriatric syndromes including cognitive and functional decline is limited, and some data suggest potential for harm, with studies describing association between antihypertensive therapy and higher mortality (Benetos 2015a), and serious injuries arising from falls (Tinetti 2014).

The evidence for antihypertensive therapy in people with cognitive impairment or dementia, and the impact of this treatment on cognition is uncertain, with conflicting results in published data and no meta-analysis possible due to heterogeneity (Beishon 2014). Data have variously shown a protective, harmful or neutral effect of antihypertensives on cognition. One study with almost 5000 older adults, suggested no detrimental effect of antihypertensive treatment on cognitive function in people with existing cognitive problems (Skoog 2005). Two other large studies did not show a reduction of incident dementia in people treated with antihypertensive medications (Di Bari 2001; Peters 2008). However, other work suggested a protective effect of antihypertensive treatment on vascular-induced dementia (Tzourio 2003), while another study reported potential for antihypertensive medication to accelerate cognitive decline (Alrawi 2013).

These seemingly conflicting trial data may be explained by the complex relationship between blood pressure and cognition over the life course. Hypertension in middle-age is a risk factor for incident dementia, driven at least in part by cerebrovascular disease (Norton 2014). However, the association between blood pressure and dementia at an older age is inverse (Kennelly 2009; Qiu 2009). Several years before dementia onset, a decrease in blood pressure can be seen (Skoog 1996), and low blood pressure is associated with cognitive decline in the years after diagnosis (Nilsson 2007), although the direction of causality is unknown. Several mechanisms were proposed to underlie this decrease in blood pressure in the years before the diagnosis of dementia, including autonomic dysregulation as symptom of neurodegeneration (den Abeelen 2014). The arteriosclerotic and age-related changes to cerebral blood flow autoregulation in older people could also result in cerebral hypoperfusion, potentially influencing cognitive functioning (Qiu 2009).

Thus, the evidence base for cognitive benefits of hypertension treatment in midlife is compelling, but the evidence for cognitive effects of hypertension treatment in older age is less clear. The Cochrane systematic review on hypertension treatment in elderly people showed that adherence to treatment is limited and a considerable proportion of older people discontinue treatment, due to adverse effects, in particular when the level of prescribed treatment increased (Musini 2009). Taking all this into account, there is a concern that antihypertensive medication may have potential for harm in people with cognitive impairment/dementia and it may negatively influence cognitive functioning. There is an associated debate regarding the benefit of withdrawing antihypertensive therapy in older adults, since the risk-benefit ratio of treatment might be different at differing ages and with different classes of antihypertensive medications (Shah 2009).

It would be interesting for patients, carers and policymakers if withdrawal of antihypertensive medications has a positive effect on cognitive functioning, since this might possibly lead to a decrease in dementia incidence and thus major health cost savings. Reducing medication use will also contribute to less healthcare expenditures. Such withdrawal may take place in isolation, or may be part of a wider medication review or deprescribing exercise. Deprescribing is "the process of tapering or stopping drugs, aimed at minimizing polypharmacy and improving patient outcome" and is a growing area with observation and trial evidence (Scott 2015). Older adults (Opondo 2012), care home residents (Stafford 2011), and people with advanced dementia (Tjia 2014) are all populations in whom inappropriate prescribing is thought to be common with scope for improvements through deprescribing or electronic systems for medication review.

The purpose of this systematic review was to summarise all available evidence on cognitive effects of withdrawal of antihypertensive medications and associated benefits and harms in adults (including healthy adults and people with prevalent cognitive decline).

\section{Description of the condition}

We have focused on the implications of antihypertensive medication on cognitive functioning, including cognitive decline and dementia. Cognitive decline is often accompanied by deterioration in emotional control, social behaviour or motivation. The number of people living with cognitive impairment not classified as dementia is probably even higher, but no exact data on this exist. The term 'mild cognitive impairment' (MCl) refers to a 'syndrome defined as cognitive decline greater than expected for an individual's age and education level but that does not interfere notably with activities of daily life' (Gauthier 2006). Although rates of conversion from $\mathrm{MCl}$ to dementia vary, it is thought that people with $\mathrm{MCl}$ are at an increased risk of developing dementia (Bruscoli 2004). The term 'dementia' refers to a group of diseases which shares a syndrome that is typically chronic and progressive in nature. The dementia syndrome involves disturbances of multiple higher cortical functions, such as memory, thinking, orientation, perception and behaviour, which are severe enough to affect the ability to perform everyday activities. Although the incidence of dementia is thought to be declining in Western countries (Matthews 2016), the prevalence is increasing due to the ageing world population meaning larger numbers of people are living with dementia (Ferri 2005). Worldwide, 47.5 million people were estimated to be affected in 2015 and it is anticipated that this figure will double by 2030 , resulting in high costs and considerable burden to individuals and societies (WHO 2015).

\section{Description of the intervention}

In this review, we identified and appraised randomised controlled trials (RCTs) and controlled clinical trials (CCTs) which evaluated the cognitive consequences of withdrawal of antihypertensive treatment in adults. For this review, we defined 'antihypertensive 
treatment' as the use of any drug with any blood pressure lowering effect, prescribed for any indication.

Major classes of antihypertensive drugs include thiazide diuretics, beta-blockers, drugs inhibiting the renin-angiotensin system, calcium channel blockers, direct vasodilators, centrally active drugs and others. The different classes of antihypertensive drugs have differential effects on some outcomes, and it is possible that they have differential effects on cognition. Some studies have suggested that especially calcium channel blockers (Yasar 2005) and diuretics (Khachaturian 2006; Qui 2003) may have a protective effect on cognition, but this has not been shown in a RCT.

\section{How the intervention might work}

There are plausible theoretical reasons why withdrawal of antihypertensive therapy may have a beneficial effect on cognition. One of these reasons might be autonomic dysregulation as symptom of neurodegeneration (den Abeelen 2014). Another theory is about arteriosclerotic and age-related changes to cerebral blood flow autoregulation in older adults, resulting in cerebral hypoperfusion (Qiu 2009) and potentially influencing cognitive functioning. Equally, withdrawal of antihypertensive therapy may accelerate cognitive decline through incident stroke or progression of small vessel disease.

Interventions to completely withdraw at least one antihypertensive medication in people with and without cognitive problems may also reduce adverse effects and improve quality of life for the patient and carer. However, they may also cause withdrawal symptoms such as 'rebound' tachycardia with withdrawal of beta-blocker, headache, agitation and nausea (Karachalios 2005). Therefore, we have examined trials which evaluate effects of antihypertensive withdrawal, contributing to the evidence base in this area.

\section{Why it is important to do this review}

Contemporary guidelines for blood pressure management in older adults focused on indications for treatment and choice of treatment. It is possible that withdrawal of antihypertensive medication in certain older- adult populations may have beneficial effects on cognition or rates of incident dementia, or both. A cost saving intervention (drug withdrawal) that impacts on cognition would have important individual and public health implications. Drug withdrawal might also decrease the burden of polypharmacy. This burden is usually accompanied with minor and major adverse events, so withdrawal of drugs may have a positive impact. A synthesis of all relevant data moves us closer to adopting evidence- based interventions, or identifies the evidence gaps that require further original research. In general, studies that address the effect of withdrawal of drugs in adult populations are highly relevant to prevent unnecessary and potentially harmful treatments. It is recognised that the initiation and continuation of inappropriate medications is known to negatively impact on the safety of patients (Anathhanam 2012), thus medication withdrawal has the potential to improve safety, provided it does not come with additional greater risks. Finally, improved understanding of medication withdrawal is of particular interest to patients who should be active participants in any deprescribing process. Exploring and addressing their concerns and understanding is critical in successful withdrawal (Reeve 2013), and improving the evidence base behind recommendations is a key component of this.

\section{O B JECTIVES}

To assess the effects of complete withdrawal of at least one antihypertensive medication on incidence of dementia, cognitive function, blood pressure and other safety outcomes in cognitively intact and cognitive impaired adults.

\section{METHODS}

\section{Criteria for considering studies for this review}

\section{Types of studies}

We selected studies if they met the following criteria: RCTs comparing withdrawal of antihypertensive medications with continuation of the medications. We also included CCTs that meet other inclusion criteria. An outcome measure assessing cognitive function or dementia diagnosis had to be clearly defined.

\section{Types of participants}

Participants were aged 18 years and over. Participants must have been taking the antihypertensive medications for a minimum of one month irrespective of indication.

Participants could reside in any healthcare setting (including acute hospitals, nursing and residential homes, and the community). We included healthy participants and participants with all grades of severity of existing dementia or cognitive impairment.

\section{Types of interventions}

Withdrawal of any medication with blood pressure lowering effects (see list of relevant medications included in Appendix 1) with no restriction to duration of follow-up.

\section{Types of outcome measures}

\section{Primary outcomes}

- Cognitive impairment or rates of incident dementia in cognitively intact and cognitively impaired adults.

- Cognition in the short-term in adults with or without established cognitive impairment.

Cognitive function quantified with a recognised assessment instrument including multiple cognitive domains, for example (but not limited to) Folstein's Mini Mental State Examination (MMSE) (Folstein 1975), Montreal Cognitive Assessment (MoCA) (Nasreddine 2005), more extensive neuropsychological testing, or formal clinical diagnosis of dementia according to current internationally accepted guidelines, for example (but not limited to) International Classification of Diseases and Related Health Problems (ICD-10) and Diagnostic and Statistical Manual of Mental Disorders (DSM-IV).

\section{Secondary outcomes}

- Changes in systolic and diastolic blood pressure.

- Rates of (serious) adverse events across the included studies. These included mortality, cardiovascular events, early (within first eight weeks) and late (post-six months) adverse effects (e.g. falls and hospitalisation). 
- Adherence to withdrawal of the antihypertensive medications. We defined adherence to withdrawal as participants remaining off medication for the duration of the study or at least six months, whichever was longer.

\section{Search methods for identification of studies}

We used the electronic databases listed below to search for relevant studies regardless of language, personnel, research setting or date of publication.

\section{Electronic searches}

We searched ALOIS (www.medicine.ox.ac.uk/alois) - the Cochrane Dementia and Cognitive Improvement Group's (CDCIG) specialised register on 12 December 2015.

ALOIS is maintained by the Trials Search Co-ordinator for the $\mathrm{CDCIG}$, and contains studies that fall within the areas of dementia prevention, dementia treatment and management, and cognitive enhancement in healthy older adult populations. The studies are identified through:

- monthly searches of a number of major healthcare databases: MEDLINE, Embase, CINAHL, PsycINFO and LILACS;

- monthly searches of a number of trial registers: ISRCTN; UMIN (Japan's Trial Register); the World Health Organization (WHO) portal (which covers ClinicalTrials.gov; ISRCTN; the Chinese Clinical Trials Register; the German Clinical Trials Register; the Iranian Registry of Clinical Trials and the Netherlands National Trials Register, plus others);

- quarterly search of the Cochrane Central Register of Controlled Trials (CENTRAL); and

- six-monthly searches of a number of grey literature sources: ISI Web of Knowledge Conference Proceedings; Index to Theses and Australasian Digital Theses.

To view a list of all sources searched for ALOIS see AboutALOIS on the ALOIS website (www.medicine.ox.ac.uk/alois).

Details of the search strategies run in healthcare bibliographic databases, used for the retrieval of reports of dementia, cognitive improvement and cognitive enhancement trials, can be viewed in the 'Methods used in reviews' section within the editorial information about the Cochrane Dementia and Cognitive Improvement Group.

We ran additional searches in MEDLINE, Embase, PsycINFO, CINAHL, LILACS, Web of Science core collection, ClinicalTrials.gov and the WHO Portal/ICTRP to ensure that the search was as comprehensive and up-to-date as possible. See Appendix 2 for the search strategy that we used to retrieve reports of trials from MEDLINE (via the OvidSP platform).

\section{Searching other resources}

In case of incomplete reports or conference abstracts, we conducted further searches for connected papers and, if necessary, we contacted authors to obtain missing information.

We handsearched the reference lists of the relevant articles that we retrieved and searched for non-MEDLINE listed journals. We also searched the Science Citation Index for articles citing key references. We emailed two North American research groups with active deprescribing research programmes to check we had not missed any relevant studies.

\section{Data collection and analysis}

\section{Selection of studies}

Phase 1: two review authors ( $\mathrm{SJ}$ and $\mathrm{JH}$ ) independently performed searches and screening of identified studies. We independently examined titles and abstracts of citations obtained from the searches and discarded obviously irrelevant articles. At this stage, we were overly inclusive; we retrieved for further assessment any article that suggested a relevant study.

Phase 2: from the potentially relevant articles in Phase 1, two review authors (SJ and $\mathrm{JH}$ ) independently selected studies (based on the full-text format) for inclusion. We resolved disagreement on study inclusion by consensus or third party adjudication (ER).

We detailed the study selection process in a PRISMA flow diagram (Moher 2009; Figure 1). 
Figure 1. PRISMA Study flow diagram.

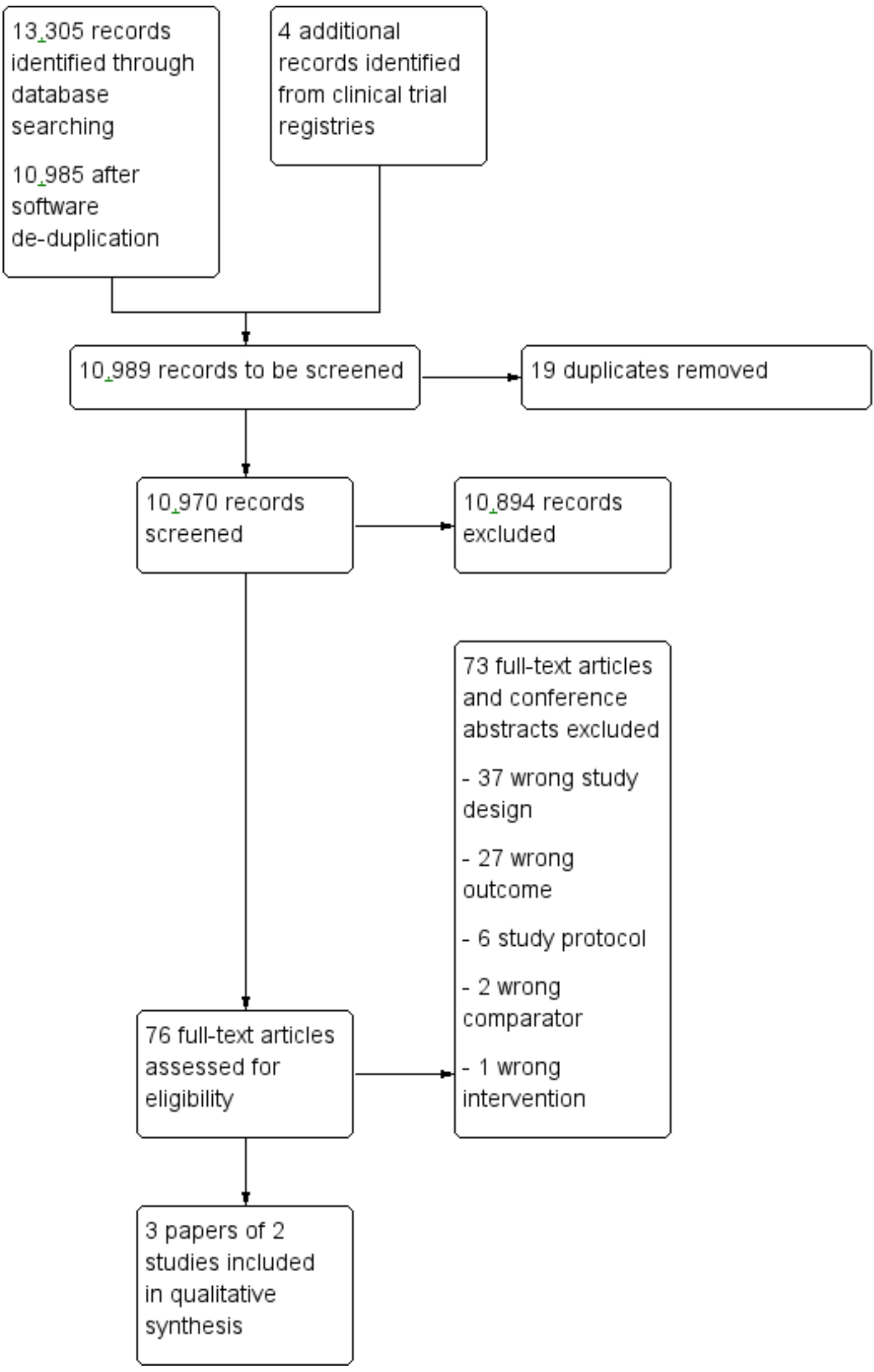




\section{Data extraction and management}

Two review authors (SJ and $\mathrm{JH}$ ) independently performed data extraction using a prespecified data extraction form and entered the data into Review Manager 5 software (RevMan 2014). In case of discrepancies, we involved a third review author (ER) until we reached consensus.

We created and used a specific data extraction form, including source, methods, participants, interventions, outcomes, results, funding source and declarations of interest according to the Cochrane Handbook for Systematic Reviews of Interventions guidance (Higgins 2011).
One review author (SJ) entered the data into Review Manager 5, which were checked for accuracy by a second review author (JH) (RevMan 2014).

\section{Assessment of risk of bias in included studies}

Two review authors (SJ and $\mathrm{JH}$ ) independently assessed the internal validity of each included study. We described the risk of bias of all included studies in the Characteristics of included studies table and narrative. We used the Cochrane 'Risk of bias' tool for assessment and we used seven standard criteria: random sequence generation; allocation concealment; blinding of participants and personnel; blinding of outcome assessment; incomplete outcome data; selective reporting and other risk of bias (Higgins 2011). We assessed every study for each of the seven criteria and reported the information in a 'Risk of bias' table in Figure 2.

Figure 2. Cochrane 'Risk of bias' summary: review authors' judgements about each risk of bias item for each included study.

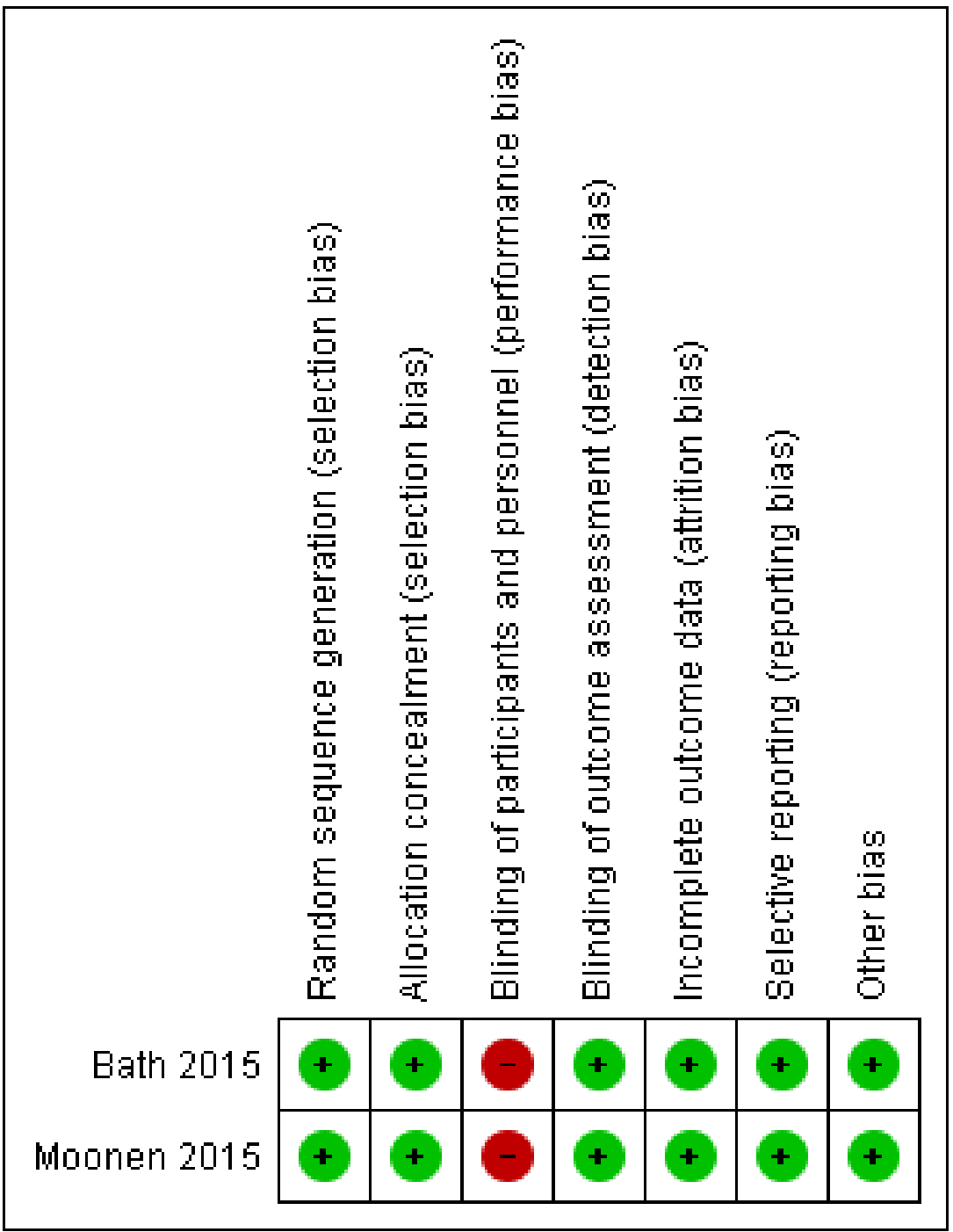

\section{Measures of treatment effect}

We used mean differences (MD) or standardised mean differences (SMD) with 95\% confidence intervals (CI) for continuous outcomes, and risk ratios (RR) with $95 \% \mathrm{Cls}$ for the analysis of dichotomous outcomes. 
Scales that are commonly used in dementia trials are often coded ordinally. We treated the data measured with scales comprising of more than 10 categories as continuous variables assuming a normal distribution.

\section{Unit of analysis issues}

The unit of analysis was the person undergoing the withdrawal of an antihypertensive treatment. As defined in our protocol, we considered for each study whether groups of individuals were randomised together to the same intervention (i.e. clusterrandomised trials), whether individuals underwent more than one intervention (e.g. in a cross-over trial) or whether there were multiple observations for the same outcome (e.g. repeated measurements, recurring events).

\section{Dealing with missing data}

For each outcome measure, we sought data on every participant assessed. To allow an intention-to-treat analysis, we sought the data irrespective of compliance, whether the participant was subsequently deemed ineligible, or otherwise excluded from treatment or follow-up. We did not use data from titration phases prior to the randomised phase to assess safety or efficacy. We made a qualitative judgement as to whether to exclude studies if the impact of missing data was too large.

\section{Assessment of heterogeneity}

We considered clinical heterogeneity between trials (participants, interventions and outcomes) when deciding whether to synthesise data. Statistical heterogeneity was considered by using the 12 test (Higgins 2011). We considered heterogeneity of $30 \%$ to $60 \%$ as moderate, $50 \%$ to $90 \%$ as substantial and $75 \%$ to $100 \%$ as considerable. We made a decision on the appropriateness of metaanalysis based on statistical and clinical heterogeneity.

\section{Assessment of reporting biases}

We searched for non-published as well as published studies in databases and trial registries, to avoid publication bias. To avoid language bias, we did not employ language restrictions for included studies. Where there are multiple publications from one study, we only included the primary publication to address duplicate publication bias.

\section{Data synthesis}

We decided on suitability of meta-analysis for each outcome by a qualitative assessment (including statistical and clinical heterogeneity) of the included studies.

We conducted data synthesis and analyses using Review Manager 5 software (RevMan 2014). We planned to use RRs and a randomeffects model to combine outcomes across trials for a metaanalysis. The weighting factor for each study would be the inverse of the within-study variance plus a between-study variance component.

\section{Subgroup analysis and investigation of heterogeneity}

If we had identified 10 or more trials that contributed to the analyses of primary outcomes, we planned to perform stratified analyses of the primary effectiveness outcome according to the following trial characteristics: presence versus absence of dementia or cognitive impairment at baseline, age and type/ class of antihypertensive treatment (thiazide diuretics, angiotensin converting enzyme inhibitors (ACE-I), etc.).

\section{Data presentation - 'Summary of findings' tables}

We used the GRADE approach to assess the quality of the supporting evidence behind each estimate of treatment effect (Schünemann 2011a; Schünemann 2011b). We presented key findings of the review including a summary of the amount of data, the magnitude of the effect size and the overall quality of the evidence, in a 'Summary of findings' table, created using GRADEproGDT software (GRADEproGDT 2015). We preselected the following outcomes: cognitive impairment (incident dementia (clinical diagnosis) and change in a validated cognitive test score); change in systolic and diastolic blood pressure; mortality; cardiovascular events; falls; hospitalisation and adherence to withdrawal. Following guidance from the CDCIG editorial team, we decided to exclude change in systolic and diastolic blood pressure and adherence to withdrawal outcomes from presentation in the table.

\section{Sensitivity analysis}

We planned to perform a sensitivity analysis for pooled results based on methodological quality. We also planned to perform sensitivity analyses without CCTs (if identified) to look at the effect of these studies and to avoid risk of bias from the non-randomised design. These sensitivity analyses could not be performed due to the inclusion of only two studies, so there was not enough data to pool.

\section{RES U L T S}

\section{Description of studies}

\section{Results of the search}

The electronic searches performed on 12 December 2015 retrieved 10,989 results. After initial de-duplication two review authors (SJ and $\mathrm{JH}$ ) independently assessed the remaining 10,970 references for relevance. We received no information for further published or unpublished studies from experts or manufacturers. We excluded 10,894 references that were not relevant on title and abstract screening. Two review authors ( $\mathrm{S}$ and $\mathrm{JH}$ ) independently assessed 76 full-text articles and conference abstracts for eligibility. Seventythree articles did not meet our inclusion criteria and were excluded. We included three articles referring to two trials (Bath 2015; Moonen 2015). The selection process is summarised in the PRISMA diagram (Figure 1).

\section{Included studies}

We identified two trials for inclusion with 2490 randomised participants (Bath 2015; Moonen 2015). Bath 2015 is known as the 'Efficacy of nitric oxide, with or without continuing antihypertensive treatment, for the management of high blood pressure in stroke (ENOS) study'. Moonen 2015 is known as the 'Discontinuation of antihypertensive treatment in elderly people on cognitive functioning (DANTE) study'. In addition to the Characteristics of included studies table, we reported additional information on the included studies in Table 1. We did not contact the authors of either of the included studies since this was not deemed necessary. 


\section{Participants}

The ENOS study randomised 4011 participants, although only 2097 participants were included in the antihypertensive withdrawal substudy, as the remainder were not taking antihypertensive medication before admission (Bath 2015). Participants who were included in the antihypertensive withdrawal substudy had a more severe phenotype than those who were not taking antihypertensive drugs before randomisation; they were older, more likely to be women, had higher rates of vascular risk factors and were less likely to have a normal premorbid Rankin Scale score. The DANTE study randomised 393 participants (Moonen 2015).

The populations recruited into the two studies were clinically distinct. In Bath 2015, all participants had to have experienced an acute stroke, while in Moonen 2015, all participants had $\mathrm{MCl}$ (defined as an MMSE score between 21 and 27) and taking antihypertensive medications.

The mean age of participants in the DANTE study was 81 years (Moonen 2015), in comparison with 73 years in the ENOS study (Bath 2015). Moonen 2015 only included people aged 75 years and older. Men were $39 \%$ to $42 \%$ of the study population in DANTE in comparison with $50 \%$ to $52 \%$ of the study population in ENOS.

Both studies reported comorbidities at baseline and these seemed comparable between intervention and control groups (Bath 2015; Moonen 2015).

Systolic blood pressure was higher at baseline in the ENOS study at $166 \mathrm{mmHg}$ to $168 \mathrm{mmHg}$ (Bath 2015) in comparison to $147 \mathrm{mmHg}$ to $148 \mathrm{mmHg}$ in the DANTE study, whose eligibility criteria limited systolic blood pressure to $160 \mathrm{mmHg}$ (Moonen 2015).

Moonen 2015 assessed cognitive status at baseline and followup, while in Bath 2015, cognitive status was unknown at baseline and only evaluated at follow-up. One study excluded people with dementia (Moonen 2015).

Only one study reported level of education at baseline, which was comparable between groups (Moonen 2015).

Both studies included participants taking any classes of antihypertensive treatment. Most participants in both studies were taking more than two antihypertensive medications, more than $60 \%$ of participants in DANTE (Moonen 2015) and more than $50 \%$ of participants in ENOS (Bath 2015). Diuretic use was higher in DANTE (54\%) than ENOS (16\%) and ACE-I use was lower in DANTE (35\%) than ENOS (48\%).

\section{Setting}

The two clinical settings also varied. Bath 2015 was a large international multicentre study conducted in acute hospital settings, recruiting participants at hospital admission. More than $60 \%$ were recruited in the UK, with the remainder worldwide (Bath 2015). Moonen 2015 was conducted in primary care in the Leiden region of the Netherlands, with participants recruited by general practitioners (GPs).

\section{Interventions and comparators}

The interventions reported in each of the studies vary in duration of antihypertensive withdrawal from seven days (Bath 2015) to three months (Moonen 2015).
Bath 2015 was a parallel-group design RCT with four groups. The entire sample was randomised to receive a glyceryl trinitrate (GTN) patch (intervention) or no patch (control). All participants who were taking antihypertensive medications prior to admission (2097/4011 participants) were then additionally randomised to stop their antihypertensive medications (intervention) or to continue preexisting antihypertensive medications (control). Both the GTN intervention and antihypertensive withdrawal were for the first seven days following an acute stroke admission. Thereafter medications could be prescribed or reintroduced as clinically indicated.

Moonen 2015 was a parallel-group design RCT with two groups. Over an initial six-week period, antihypertensive medications were withdrawn by the participant's GP using a withdrawal algorithm designed by the study authors. This was done provided systolic blood pressure did not exceed $180 \mathrm{mmHg}$. Medication withdrawal was completed within four weeks from randomisation and continued for a period of three months thereafter.

\section{Funding sources}

The UK Medical Research Council funded Bath 2015 and a grant from the Program Priority Medicines for the Elderly, the Netherlands Organization for Health Research and Development, funded Moonen 2015.

\section{Excluded studies}

We excluded 77 publications, conference abstracts and registered trials and presented the reasons for exclusion in the Characteristics of excluded studies table. Reasons for study exclusion were: wrong study design (not an RCT or CCT); wrong outcome measure (lack of cognitive outcome measure used); wrong comparator (the study did not compare participants withdrawing antihypertensive medications with participants continuing them); wrong intervention (participants were not randomised to withdraw or continue antihypertensive medications) and study protocol (planned work without results reported; none met our eligibility criteria for inclusion as ongoing studies).

\section{Risk of bias in included studies}

Overall, the quality of included studies was high (see Characteristics of included studies table, Figure 2), with the exception of high risk for performance and attrition bias in both studies.

\section{Allocation}

Both studies were at low risk of selection bias as they used a central computerised randomisation procedure for allocation of participants. Stratification was used to ensure that the groups were balanced and key parameters appeared adequately divided between intervention and control groups in each study.

\section{Blinding}

Both studies were at high risk of performance bias as neither masked the participants or medical personnel associated with the study to the treatment allocation. No placebo medications were administered to participants who had usual antihypertensive therapy withdrawn. Since the outcome measurement in each of the two studies was blinded, this minimised the effect of bias on the different outcome measures. 
Both studies were at low risk of detection bias as outcome assessment was conducted independently of the study team and assessors were masked to the treatment allocation of the participants.

\section{Incomplete outcome data}

Overall, the risk of attrition bias was low for both studies because they applied an intention-to-treat analysis. With respect to the primary outcome of this review, cognitive performance, both studies were at high risk for attrition bias. We graded this as high risk for attrition bias according to the GRADEproGDT 2015 guidelines and reported this in Summary of findings for the main comparison. Although both studies presented an intention-to-treat analysis for their results, not all surviving participants received cognitive testing at follow-up and the studies did not report the reasons to account for missing data. Bath 2015 reported cognitive assessment on 1272 (telephone Mini-Mental State Examination ( $\mathrm{t}$ MMSE) score) and 1179 (Telephone Interview for Cognitive Status (TICS-M) score), although 1784 survived at 90 days. Moonen 2015 reported the intention-to-treat analysis for 356 participants, while they randomised 388 participants. From those 356 participants, data were missing for three in the intervention group and two in the control group for their primary outcome (overall cognitive function).

\section{Selective reporting}

Both studies were at low risk of reporting bias as outcomes were reported as described in the published protocols. The protocol for Moonen 2015 was included in the published paper as a supplemental appendix and the analysis plan for Bath 2015 was published separately (Bath 2014).

\section{Other potential sources of bias}

Both studies were at low risk for other potential sources of bias as none were identified.

\section{Effects of interventions}

See: Summary of findings for the main comparison Antihypertensive withdrawal for the prevention of cognitive decline

See Summary of findings for the main comparison for an overview of the results.

\section{Primary outcomes}

\section{Incident dementia}

Neither study evaluated the presence of incident dementia at follow-up.

\section{Change in cognitive test scores \\ Cognitive function (at 90 days)}

Bath 2015 report data at 90 days for cognitive assessment conducted via the telephone. The numbers assessed in each group were not reported and so the denominator used was the number alive at 90 days. It is recognised this is an overestimate as the number alive at 90 days was 1784 , whereas the number who received a t-MMSE was 1272 and the TICS-M was 1179 .

The t-MMSE score was a mean of 1.0 point higher in participants who withdrew antihypertensive medications compared to participants who continued them $(95 \% \mathrm{Cl} 0.35$ to $1.65 ; 1784$ participants). The TICS-M was a mean of 2.10 points higher $(95 \% \mathrm{CI}$ 0.69 to $3.51 ; 1784$ participants) (Figure 3; Figure 4). However, in both cases, the evidence was of very low quality (downgraded due to risk of bias from missing cognitive outcome data, evidence from a single study and indirectness).

Figure 3. Forest plot of comparison: 1 Cognitive function (at 90 days), outcome: 1.1 Telephone Mini-Mental State Examination score.

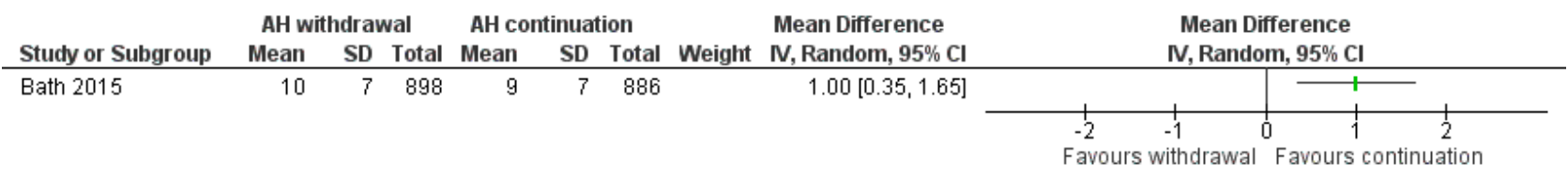

Figure 4. Forest plot of comparison: 1 Cognitive function (at 90 days), outcome: 1.2 Modified Telephone Interview for Cognitive Status score.

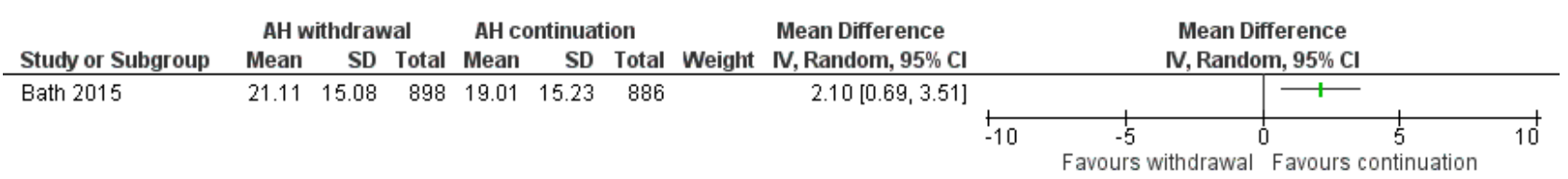

\section{Change in cognitive performance (over 16 weeks)}

Moonen 2015 report data for $351 / 388$ participants on their primary outcome of cognitive performance using a composite of at least five out of six cognitive tests. A higher score represented a better cognitive performance. There was no evidence of a mean difference in cognitive performance between participants who withdrew antihypertensive medications than participants who continued (MD 0.02 points, $95 \% \mathrm{Cl}-0.19$ to $0.23 ; 351$ participants) (Figure 5). This evidence was of low quality (downgraded due to risk of bias from missing cognitive outcome data and evidence from a single study). 
Figure 5. Forest plot of comparison: 2 Change in cognitive function (over 16 weeks), outcome: 2.1 Composite score.

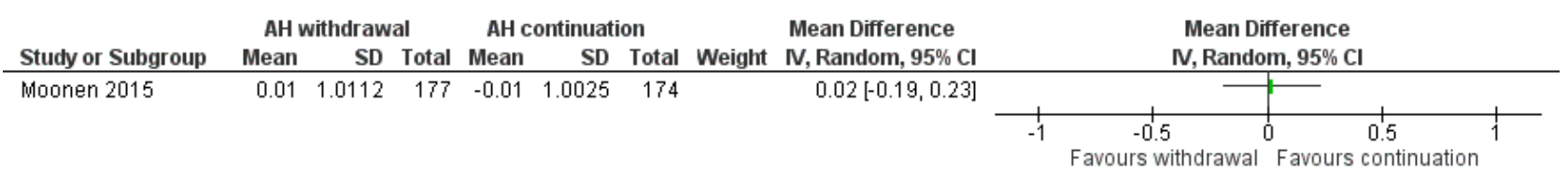

Each of the six cognitive tests were reported independently for 356/388 randomised participants. There was no evidence of change in cognitive performance in participants who withdrew medications using the MMSE score (MD 0.34 points, $95 \% \mathrm{Cl}-0.08$ to 0.76 ; 356 participants); the 15 -Word Verbal Learning Immediate Recall score (MD 0.24 points, $95 \% \mathrm{Cl}-0.66$ to $1.14 ; 356$ participants); the Delayed Recall score (MD 0.16 points, $95 \% \mathrm{Cl}-0.29$ to 0.61 ; 356 participants); or the Visual Association Test score (MD 0.14 points, $95 \% \mathrm{Cl}-0.17$ to $0.45 ; 356$ participants). This evidence was low quality (downgraded due to risk of bias from missing cognitive outcome data and evidence from a single study).

There was no evidence of change in cognitive performance in participants who withdrew medications using the Stroop Interference score (MD -2.22 points, $95 \% \mathrm{Cl}-9.62$ to 5.18; 356 participants) or the Trail Making Tests score (MD 10.06 points, 95\% $\mathrm{Cl}-2.20$ to 22.32 ; 356 participants). In both cases, evidence was very low quality (downgraded due to risk of bias from missing cognitive outcome data, imprecision and evidence from a single study).

\section{Secondary outcomes}

\section{Change in systolic and diastolic blood pressure}

\section{Blood pressure at seven days}

Systolic and diastolic blood pressure was assessed in 2095/2097 participants in Bath 2015, with missing data for the other two participants. After seven days, systolic blood pressure was 9.5
$\mathrm{mmHg}$ higher in the intervention compared to the control group (95\% Cl 7.43 to $11.57 ; 2095$ participants) and diastolic blood pressure was $5.1 \mathrm{mmHg}$ higher $(95 \% \mathrm{Cl} 3.86$ to 6.34; 2095 participants). This evidence was low quality (downgraded due to indirectness from the ability to interpret these data within the wider study looking at GTN administration or not and evidence from a single study).

\section{Change in systolic blood pressure (over 16 weeks)}

Mean change in systolic and diastolic blood pressure was evaluated for the 356 participants in Moonen 2015. Systolic blood pressure increased by $7.4 \mathrm{mmHg}$ in the withdrawal group compared to the control group (95\% Cl 7.08 to $7.72 ; 356$ participants) and diastolic blood pressure increased by $2.6 \mathrm{mmHg}(95 \% \mathrm{Cl} 2.42$ to 2.78 ; 356 participants). This was moderate quality evidence (downgraded due to evidence from a single study).

\section{Adverse events}

\section{Mortality}

Both studies reported data on mortality at follow-up (16 weeks and 90 days) including all randomised participants for one study (Bath 2015), and missing data on five randomised participants in the other (Moonen 2015). There was no evidence that antihypertensive medication withdrawal affected mortality at follow-up (RR 0.88, $95 \% \mathrm{Cl} 0.72$ to $1.08, \mathrm{I}^{2}=0 \% ; 2485$ participants; 2 studies; moderate quality evidence (downgraded due to indirectness)) (Figure 6).

Figure 6. Forest plot of comparison: 4 Adverse events, outcome: 4.1 Mortality.

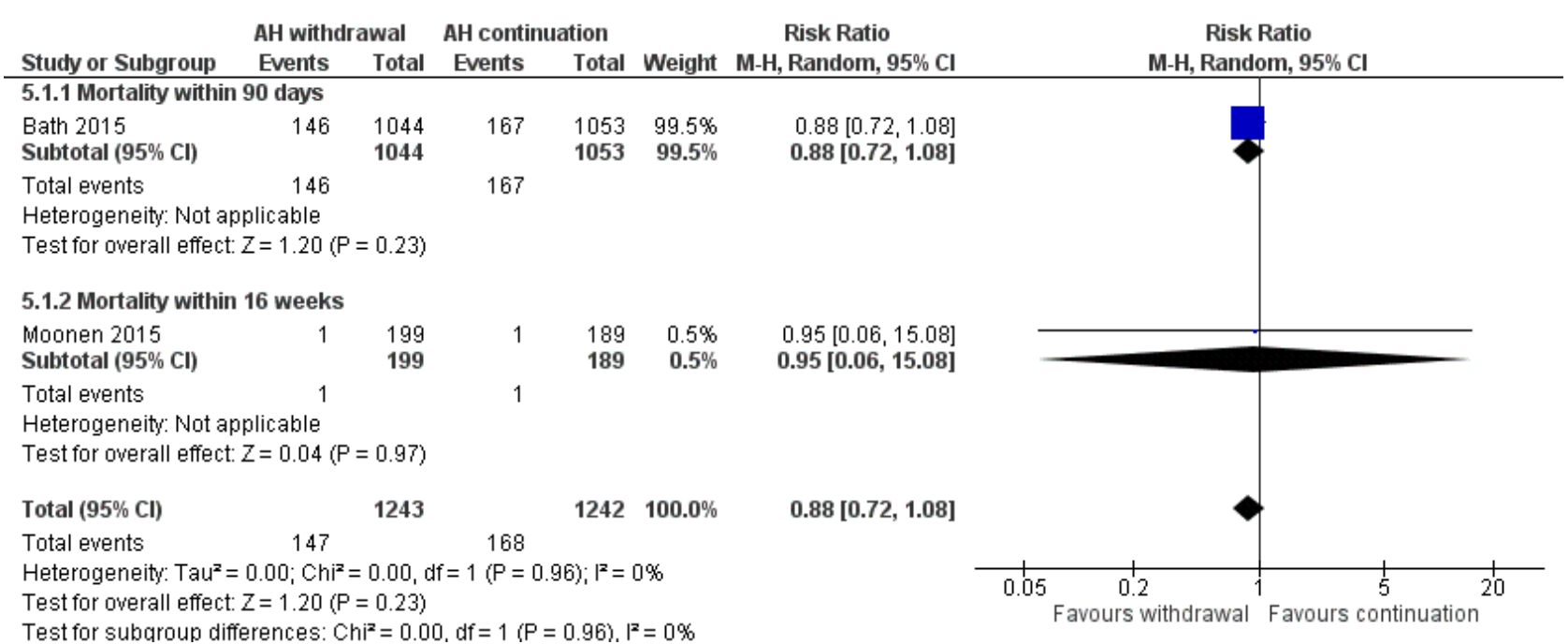

\section{Cardiovascular events}

Both studies reported on cardiovascular events during follow-up. Moonen 2015 reported only myocardial infarction, while Bath 2015 reported myocardial infarction, sudden cardiac death and other

cardiovascular events. We pooled the results and there was no evidence of effect of antihypertensive medication withdrawal on the incidence of cardiovascular events (RR $1.29,95 \% \mathrm{Cl} 0.96$ to 
$1.72 ; 1^{2}=0 \% ; 2485$ participants; 2 studies; low quality evidence

(downgraded due to imprecision and indirectness)) (Figure 7).

\section{Figure 7. Forest plot of comparison: 4 Adverse events, outcome: 4.2 Cardiovascular events.}

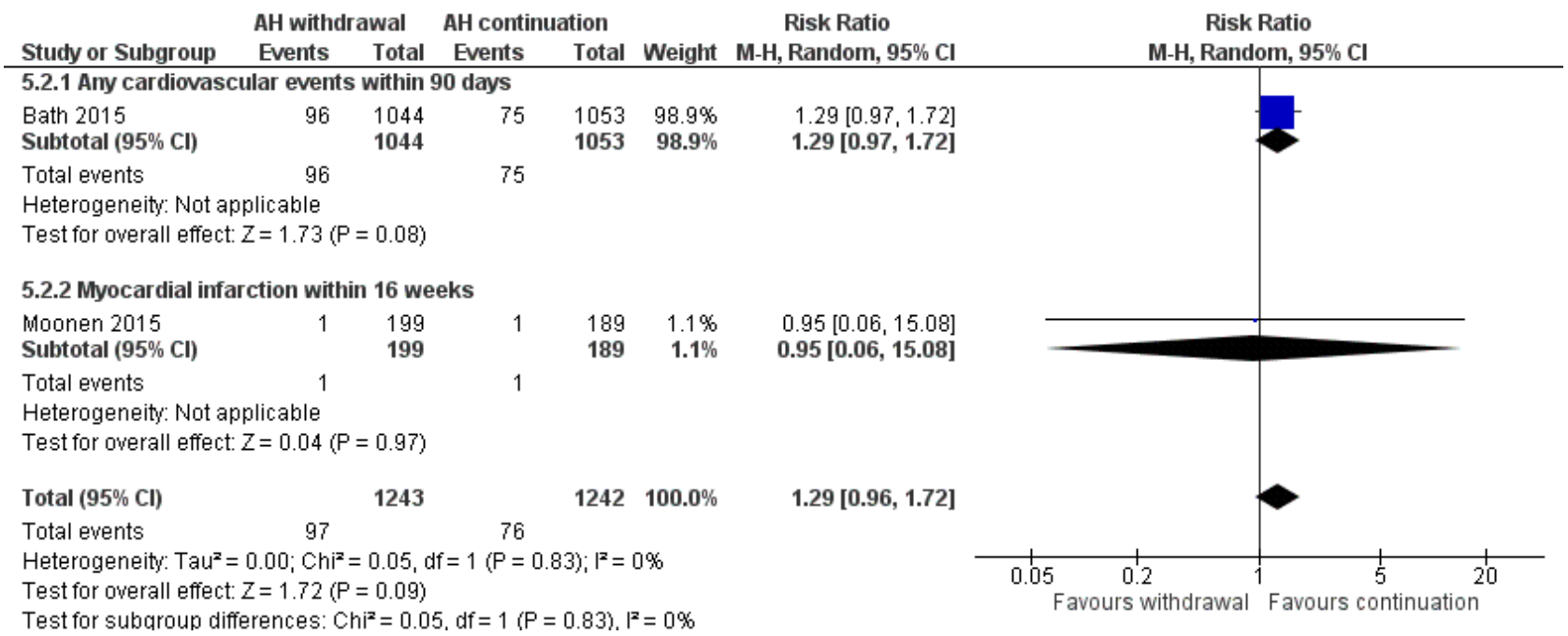

\section{Falls}

Neither study report data on incidence of falls.

\section{Hospitalisations}

Moonen 2015 reported incident hospitalisations. There was no evidence that antihypertensive withdrawal reduced the risk of incident hospitalisations ( $\mathrm{RR} 0.85,95 \% \mathrm{Cl} 0.36$ to 2.06 ; 388 participants; low quality evidence (downgraded due to imprecision and evidence from a single study)).

\section{Adherence to withdrawal}

Bath 2015 reported adherence to allocated withdrawal or continuation for the entire seven-day period of study. Data were available for 2095/2097 included participants in the continue versus stop arm. A total of $810 / 1044$ participants in the intervention group adhered to stopping antihypertensive therapy compare to $610 / 1051$ participants in the control group adhered to continuation of antihypertensive therapy. Adherence to allocated treatment was higher in participants withdrawing from antihypertensive medication than participants stopping (RR $1.34,95 \% \mathrm{Cl} 1.26$ to 1.42; 2095 participants; low quality evidence (downgraded due to indirectness and as results from a single study)).

Moonen 2015 reported no data on adherence to withdrawal of antihypertensive medications.

\section{DISCUSSION}

\section{Summary of main results}

Despite a clear increase in blood pressure in the withdrawal groups of both studies, there was no effect on cognition after seven days or 16 weeks. There was also no effect on cardiovascular events or mortality during the relatively short follow-up in the two studies. The overall quality of the data from the two included studies was high (Bath 2015; Moonen 2015). However, with respect to our primary outcome measure, cognitive function, we downgraded evidence when applying GRADE methodology (GRADEproGDT

2015). For both studies, there was a risk of bias introduced from missing cognitive outcomes data and analyses of cognition could not be pooled, meaning data in each case were from a single study. Therefore, we considered the evidence to be low quality for Moonen 2015 and very low quality for Bath 2015 as this was also considered indirect. To put these results in context, it is important to state that our assessment of quality was in relation to our specific study question and is not a statement on the quality of the included trials themselves.

\section{Dementia and cognitive performance}

Neither study evaluated development of incident dementia following medication withdrawal. This lack of evidence for a key question of interest to this review may reflect the short follow-up periods used in both studies (90 days and 16 weeks). This outcome measure is likely to require longer-term surveillance of recruited participants, but would be of particular interest for the DANTE study that included a population considered to have MCI (Moonen 2015).

The data on cognitive performance is difficult to interpret with different results depending on the cognitive measure used. Furthermore, determining the clinical significance of the changes observed is key. Bath 2015 contains very low quality evidence of improvement in cognitive performance at 90 days of follow-up; however, we do not know the baseline cognitive function of the included participants and cannot ascertain the effect of the acute event (stroke) and the other intervention studied (nitric oxide) from the effect of antihypertensive withdrawal for a seven-day period. There is also a risk of a survival bias being introduced through the study design, as only participants alive and able to complete cognitive assessment at 90 days were included. Participants who had died or could not be assessed in the telephone assessment were excluded and this reflects the lower numbers in the cognitive analyses. We had to use a proxy denominator in the form of 'alive at 90 days' to incorporate the cognitive data. This overestimates the numbers assessed and reduces confidence in the result presented. Moonen 2015 used a composite cognitive score as their primary outcome and we found low quality evidence that there was no 
evidence of effect on cognitive performance in participants who withdrew medications over the 16 -week study period, compared to participants who continued.

\section{Blood pressure}

We found low quality evidence from one study and moderate quality evidence from the other study that systolic and diastolic blood pressure rise following cessation of antihypertensive medications when compared to participants who continue therapy. This clinically plausible result is consistent; however, it does not appear to be matched with any evidence of increased mortality (moderate quality evidence) or cardiovascular events (low quality evidence). The evidence for treating hypertension in older adults has been established in randomised trials and is known to reduce cardiovascular morbidity and mortality (Musini 2009).

\section{Adverse events and safety}

A rise in blood pressure may have been anticipated to lead to a rise in adverse events. We found no evidence of a significant increase in cardiovascular events (low quality evidence) or mortality (moderate quality evidence) in either study. We recognise that the studies had a relatively short period of follow-up (months) and that it would take years of follow-up to be certain that the drug withdrawal interventions had no effect on cardiovascular events. Accepting this major caveat, as detailed in our protocol, we pooled data from the available studies for common endpoints of mortality and cardiovascular events. These pooled data suggested no evidence of effect of antihypertensive medication withdrawal on the incidence of cardiovascular events or mortality across the studies, albeit the ENOS study (Bath 2015) contributes almost all the data.

\section{Adherence to withdrawal}

The results on adherence to withdrawal are difficult to interpret as they could only be extracted from one study (Bath 2015), and this also evaluated the effects of another medication (GTN) which may lower blood pressure. It is difficult to conclude what effect this had on the adherence of participants allocated to either arm of the study. Data were not reported for participants who recommenced medications in Moonen 2015 despite the inclusion of criteria for reintroduction of medications.

\section{Overall completeness and applicability of evidence}

Only one of the studies identified for inclusion in the review aligned with our study question of interest, namely to examine the cognitive effects of antihypertensive medication withdrawal (Moonen 2015). Cognition was a secondary outcome measure used by Bath 2015, whose primary question of interest was the safety and efficacy of nitric oxide in the context of acute stroke, with or without continuing existing antihypertensive therapy. This affects the extractable data available and limits the ability to compare the two interventions.

Furthermore, although both populations were at high risk of cognitive decline, the mechanism for these was clinically distinct. Bath 2015 recruited people hospitalised for acute stroke who were recruited into an intervention study of nitric oxide. Here the expected rationale for withdrawing antihypertensive medication would be to maintain or augment blood pressure during an acute (seven-day) period following stroke where it may be plausible to anticipate cerebral perfusion is acutely compromised
(Markus 2004). Moonen 2015 recruited community-dwelling older adults with evidence of reduced cognitive performance where withdrawing medication could be considered to improve cerebral blood flow where brain perfusion may be chronically impaired (Mossello 2015). Both represent questions of clinical uncertainty and areas of variation in practice.

The procedure for medication withdrawal in Moonen 2015 was described in full in the supplementary material, overseen by the participants' GPs. The procedure used by Bath 2015 was not clearly described. Many participants in the control group also experienced withdrawal of their medication as a consequence of impaired swallow following acute stroke, for part or all of the seven-day period and only $67.8 \%$ of participants were adherent for all seven days.

A particular limitation of the data presented is the inability to combine cognitive scores and blood pressure data due to the variations in reporting between the papers. One argument is that the populations were too distinct to pool data. However, if we are to make best use of all available clinical trial data, greater effort must be made in the reporting of outcomes using a more standardised approach. Even if the data had been presented in the same format, we could not have pooled scores as the measures used and the interventions itself were heterogeneous. This is an area of interest beyond the scope of this review, reflected in international efforts to standardise outcome measure reporting (ICHOM 2016). Additionally, for some of the cognitive outcome measures used in the included studies (t-MMSE in Bath 2015 and cognitive composite score in Moonen 2015), the clinical significance of change in the cognitive test scores is uncertain and this makes a result difficult to interpret on a population level.

Also, neither study focused on the withdrawal of one particular antihypertensive drug (class). Participants were allowed to stop their previously described antihypertensive medications irrespective of the class. We planned to do a subgroup analysis for the different classes of antihypertensives, but due to a lack of data, this could not be done.

Finally, the extent of excluded studies in relation to those eligible for inclusion is important to explore. Two common reasons included the design of the study, principally those identified were observational in design and the lack of use of any cognitive outcome measure at follow-up. The search strategy for this review was comprehensive and designed to incorporate all studies looking at the withdrawal of antihypertensive medications. However, current indexing does not readily identify medication withdrawal studies and this is an additional issue which would benefit from further collaborative work to more easily identify deprescribing studies.

\section{Quality of the evidence}

Data from the two RCTs (2135 participants) could not be pooled for analysis of change in cognitive test score. Evidence was of low quality in relation to cognitive performance. Evidence was downgraded in Moonen 2015 due to risk of bias from incomplete outcome data and assessment of cognitive outcomes and evidence being from a single study. Evidence from Bath 2015 was downgraded to very low quality for the same risk of bias and evidence from a single study plus the indirectness associated with the comparison between blood pressure lowering with GTN 
and potential interaction with the intervention studied (namely antihypertensive medication withdrawal) as we could not establish who was in the GTN and placebo study arms.

Data from the two RCTs (2135 participants) could not be pooled for analysis of change in blood pressure due to the different reported measures included and clinically distinct periods evaluated. There was low quality evidence of mean systolic and diastolic blood pressure being higher after seven days in participants who stopped antihypertensive medications compared to participants who continued them in Bath 2015, downgraded due to risk of indirectness from the other intervention under study (GTN administration) and evidence from a single study. There was moderate quality evidence of mean rise in both systolic and diastolic blood pressure after 10 weeks of follow-up after antihypertensive medication withdrawal (total study period 16 weeks) in Moonen 2015, downgraded as evidence was from a single study.

On the basis of two RCTs ( 2485 participants) there was no evidence of effect on mortality or cardiovascular events. However, evidence for mortality was downgraded to moderate quality due to the risk of indirectness associated with the majority of the participants being people with acute stroke compared to community dwellers with $\mathrm{MCl}$. The evidence for cardiovascular events was low quality in view of the same indirectness plus imprecision in the result.

Adherence to withdrawal could only be assessed in one study (2095 participants) and the evidence here was considered low quality, downgraded due to indirectness from the potential use of GTN and the evidence being from a single small study.

No data were available on incidence of dementia or falls.

\section{Potential biases in the review process}

This review has followed Cochrane procedures and there were only minor amendments to the review process from those stated in the protocol, outlined in Differences between protocol and review.

\section{Agreements and disagreements with other studies or reviews}

Cognitive impairment is considered as a significant factor in deprescribing decision-making by geriatricians (Ni Chroinin 2015) and the lack of evidence for people with established dementia needs to be addressed. Much of the developing evidence in this area is not class-specific and is targeted at reducing the overall burden of unnecessary medication use, particularly in the frail older-adult population (Tjia 2013). One limitation of our approach may be the focus on a single drug class, although this benefits from clarity in observing the effect of withdrawal on drug-specific outcome measures.

Antihypertensive medication withdrawal is a topic of interest not only limited to cognitive effects. We await the results of a UK feasibility study of antihypertensive medication withdrawal for people with dementia (van der Wardt 2016).

There are other systematic reviews that have been looking to the protecting effects of antihypertensive medications on cognition (Levi Marpillat 2013; Tully 2016; Zhuang 2016), most of them showing a protective effect of one or more drug classes. Despite these results, it is also important to look at the effect on cognition with drug withdrawal, since this reduces the polypharmacy and is more cost-effective than continuing or introducing drugs.

This review is one of a suite of Cochrane Reviews, looking at withdrawal of specific drug(s) or drug classes in the context of cognition. An additional Cochrane Review, describing antihypertensive withdrawal with a non-cognitive focus is underway and will provide complementary data.

\section{AUTHORS' CONCLUSIONS}

\section{Implications for practice}

It is uncertain whether withdrawal of antihypertensive medications has an influence on cognition or can prevent dementia or cognitive impairment in healthy adults or adults with impaired cognition. Withdrawing antihypertensive drugs was associated with increased blood pressure levels. It is unlikely to increase mortality at three to four months' follow-up, although there was a signal from one large study looking at withdrawal after stroke that withdrawal was associated an increase in cardiovascular events.

\section{Implications for research}

Review of the included and excluded studies suggests possible avenues for future drug withdrawal study design and conduct. For our primary focus of antihypertensives and cognition, further research should include older people and have suitably long follow-up to capture changes in rates of cognitive decline or incident dementia. A classical randomised controlled trial (RCT) design can be used for deprescribing, just as it can for studies of new drugs, although the need for a placebo or an alternative treatment in the withdrawal group is debatable. For studies of withdrawal of a drug class, such as antihypertensives, matched placebos would be almost impossible to achieve for all different kinds of antihypertensive treatment. Ideally, new RCTs looking at withdrawal of antihypertensives (or other drugs) should standardise their cognitive and other outcome measures. There are many ways to measure cognitive function, but these are not always comparable since they may measure different cognitive domains. This heterogeneity precludes comparisons between studies and complicates meta-analysis.

Deprescribing medications in general is becoming a major subject for new research projects (deprescribing.org). Optimising medication through deprescribing can be a vital part of managing chronic conditions, reducing adverse effects and improving outcomes, including cognitive outcomes. The deprescribing rubric includes many approaches, withdrawal of all but essential drugs; withdrawal of drugs considered to have increased risk in older adults; withdrawal of drug classes and withdrawal of single agents. Each approach is suited to a particular research question. For future studies looking at antihypertensive withdrawal, a focus on one type (class) of drug may be preferable, as cognitive effects may vary with drug class and withdrawal studies which are too broad may miss important class-specific effects. The heterogeneity in approach to drug withdrawal that is included in the umbrella term 'deprescribing' complicates systematic review. To progress the deprescribing agenda, we need agreed descriptive terms for the various approaches. As the literature on deprescribing research increases, it may help future reviews if search filters for this study methodology are developed. 


\section{ACK N OWLEDGEMENTS}

We would like to acknowledge the valuable input of Sue Marcus (Managing Editor, Cochrane Dementia and Cognitive Improvement
Group (CDCIG)) and Anna Noel-Storr (Information Specialist, CDGIG) who designed the search strategy and conducted the search. 


\section{RE F E R E N C E S}

\section{References to studies included in this review}

Bath 2015 \{published data only\}

* Bath PM, Woodhouse L, Scutt P, Krishnan K, Wardlaw JM, Bereczki $D$, et al. Efficacy of nitric oxide, with or without continuing antihypertensive treatment, for management of high blood pressure in acute stroke (ENOS): a partial-factorial randomised controlled trial. Lancet 2015;385(9968):617-28.

Scutt P, Woodhouse L, Krishnan K, Bath P. Continue versus withdrawal of pre-stroke antihypertensive therapy in the first week after acute stroke: a randomised controlled trial. International Journal of Stroke. 2014; Vol. 6.

\section{Moonen 2015 \{published data only\}}

* Moonen JE, Foster-Dingley JC, de Ruijter W, van der Grond J, Bertens AS, van Buchem MA, et al. Effect of discontinuation of antihypertensive treatment in elderly people on cognitive functioning - the DANTE Study Leiden: a randomized clinical trial. JAMA Internal Medicine 2015;175(10):1622-30.

\section{References to studies excluded from this review}

\section{Aberg 1989 \{published data only\}}

Aberg H, Tibblin G. Addition of non-pharmacological methods of treatment in patients on antihypertensive drugs: results of previous medication, laboratory tests and life quality. Journal of Internal Medicine 1989;226(1):39-46.

\section{ADVANCE 2001 \{published data only\}}

Rationale and design of the ADVANCE study: a randomised trial of blood pressure lowering and intensive glucose control in high-risk individuals with type 2 diabetes mellitus. Action in Diabetes and Vascular Disease: PreterAx and DiamicroN Modified-Release Controlled Evaluation. Journal of the International Society of Hypertension 2001;19(4):S21-8.

\section{Alabaster 1983 \{published data only\}}

Alabaster SL, Gogel HK, McCarthy DM. Propranolol withdrawal and variceal hemorrhage. JAMA 1983;250(22):3047.

Alderman 1985 \{published data only\}

Alderman MH, Davis TK, Gerber LM. Step-down therapy for hypertension. Results in a community-based program. Postgraduate Medicine 1985;77(7):89-92, 96-9.

\section{Alderman 1986 \{published data only\}}

Alderman MH, Davis TK, Gerber LM, Robb M. Antihypertensive drug therapy withdrawal in a general population. Archives of Internal Medicine 1986;146(7):1309-11.

\section{Al-Qassab 1988 \{published data only\}}

al-Qassab H, Cleeves LA, Francis PL, al-Sereiti MR, Findley L, Hedges $A$. Is there a central nervous withdrawal syndrome associated with discontinuing long-term treatment with propranolol?. Human Toxicology 1988;7(3):249-54.

\section{Andersen 2003 \{published data only\}}

Andersen S, Brochner-Mortensen J, Parving HH, Irbesartan in Patients With Type 2 Diabetes and Microalbuminuria Study Group. Kidney function during and after withdrawal of longterm irbesartan treatment in patients with type 2 diabetes and microalbuminuria. Journal of the Renin-Angiotensin-Aldosterone System 2003;26(12):3296-302.

\section{Andersen 2009 \{published data only\}}

Andersen $\mathrm{K}$, Weinberger $\mathrm{MH}$, Constance CM, Ali MA, Jin J, Prescott MF, et al. Comparative effects of aliskiren-based and ramipril-based therapy on the renin system during longterm (6 months) treatment and withdrawal in patients with hypertension. Journal of the Renin-Angiotensin-Aldosterone System 2009;10:157-67.

\section{Anonymous 1975 \{published data only\}}

Anonymous. Sudden withdrawal of propranolol dangerous. Drug News 1975;7(1-12):3.

\section{Appel 1995 \{published data only\}}

Appel LJ, Espeland M, Whelton PK, Dolecek T, Kumanyika S, Applegate WB, et al. Trial of Nonpharmacologic Intervention in the Elderly (TONE). Design and rationale of a blood pressure control trial. Annals of Epidemiology 1995; Vol. 5, issue 2:119-29.

\section{Ashford 1986 \{published data only\}}

Ashford A. Abrupt withdrawal of atenolol in patients with severe angina: comparison with the effects of treatment. British Heart Journal 1986;55(1):112-3.

\section{Aylett 1994 \{published data only\}}

Aylett MJ, Creighton P, Jachuck S, Newrick D, Evans A. Withdrawing antihypertensive drugs. Lancet 1994;343(8911):1512.

\section{Aylett 1999 \{published data only\}}

Aylett M, Creighton P, Jachuck S, Newrick D, Evans A. Stopping drug treatment of hypertension: experience in 18 British general practices. British Journal of General Practice 1999;49(449):977-80.

\section{Benetos 2015b \{published data only\}}

Benetos A. Hypertensive subjects over 80 living in nursing homes: are they over-treated?. Neurologie - Psychiatrie Geriatrie 2015;15(86):89-93.

\section{Bevan 1993 \{published data only\}}

Bevan EG, Pringle SD, Waller PC, Herrick AL, Findlay JG, Murray GD, et al. Effects of atenolol withdrawal in patients on triple antihypertensive therapy. Journal of Human Hypertension 1993;7(1):89-93.

\section{Blaufox 1984 \{published data only\}}

Blaufox MD, Langford HG, Oberman A, Hawkins CM, Wassertheil-Smoller SW, Cutter GR. Effect of dietary change on the return of hypertension after withdrawal of prolonged antihypertensive therapy (DISH). Dietary Intervention Study of Hypertension. Journal of Hypertension 1984;2(3):S179-81. 
Blom 1993 \{published data only\}

Blom MW, Sommers DK. Placebo substitution for methyldopa in geriatric hypertensive patients. South African Medical Journal 1993;83(5):335-6.

\section{Böhm 2015 \{published data only\}}

Böhm M, Schumacher H, Leong D, Mancia G, Unger T, Schmieder R, et al. Systolic blood pressure variation and mean heart rate is associated with cognitive dysfunction in patients with high cardiovascular risk. Hypertension 2015;65(3):651-61.

\section{Bouzas-Mosquera 2008 \{published data only\}}

Bouzas-Mosquera A, Peteiro J, Alvarez-Garcia N. Continuation or withdrawal of beta-blocker therapy in patients admitted for heart failure. Journal of the American College of Cardiology 2008;52(24):2044-5.

\section{Boyle 1979 \{published data only\}}

Boyle RM, Price ML, Hamilton M. Thiazide withdrawal in hypertension. Journal of the Royal College of Physicians of London 1979;13(3):172-3.

\section{Braunschweig 2002 \{published data only\}}

Braunschweig F, Linde C, Eriksson MJ, Hofman-Bang C, Ryden L. Continuous haemodynamic monitoring during withdrawal of diuretics in patients with congestive heart failure. European Heart Journal 2002;23(1):59-69.

\section{Brundin 1976 \{published data only\}}

Brundin T, Edhag $\mathrm{O}$, Lundman T. Effects remaining after withdrawal of long-term beta-receptor blockade. Reduced heart rate and altered haemodynamic response to acute propranolol administration. British Heart Journal 1976;38(10):1065-72.

\section{Burton 1991 \{published data only\}}

Burton R. Withdrawing antihypertensive treatment. BMJ 1991;303(6798):324-5

\section{Charalabopoulos 2005 \{published data only\}}

Charalabopoulos K, Charalabopoulos A, Papalimneou V, Kiortsis D, Dimicco P, Kostoula OK, et al. Consequences of the discontinuation of antihypertensive treatment in successfully treated patients. International Journal of Clinical Practice 2005;59(6):704-8.

\section{Choulerton 2010 \{published data only\}}

Choulerton J, Mudd P, Mac Mahon M. Withdrawing antihypertensives on the basis of orthostatic hypotension. Age and Ageing 2010;39(4):518.

\section{Chrysant 1978 \{published data only\}}

Chrysant SG, Whitsett TL. Withdrawal of antihypertensive therapy. JAMA 1978;239(21):2241-2.

\section{Cooper 1988 \{published data only\}}

Cooper WD, Glover DR, Hormbrey JM. Symptoms in hypertensive patients: the effect of treatment withdrawal. Journal of Hypertension 1988;6(4):S629-30.

\section{Croft 1986 \{published data only\}}

Croft CH, Rude RE, Gustafson N, Stone PH, Poole WK, Roberts R, et al. Abrupt withdrawal of beta-blockade therapy in patients with myocardial infarction: effects on infarct size, left ventricular function, and hospital course. Circulation 1986;73(6):1281-90.

Cullhed 1976 \{published data only\}

Cullhed I. Withdrawal of beta adrenergic antagonist. Lakartidningen 1976;73(4):203.

Danielson 1981 \{published data only\}

Danielson M, Lundback M. Withdrawal of antihypertensive drugs in mild hypertension. Acta Medica Scandinavica 1981;646:127-31.

Danilevicius 1977 \{published data only\}

Danilevicius Z. Caution in propranolol withdrawal. JAMA 1977;237(1):53.

\section{Deckert 1994 \{published data only\}}

Deckert J, Przuntek H, Gleiter $\mathrm{CH}$. Organic anxiety syndrome after withdrawal of atenolol. American Journal of Psychiatry 1994;151(12): 1840.

\section{Düsing 2012 \{published data only\}}

Düsing R, Brunel P, Baek I, Baschiera F. Sustained decrease in blood pressure following missed doses of aliskiren or telmisartan: the ASSERTIVE double-blind, randomized study. Journal of Hypertension 2012;30:1029-40.

\section{Ekbom 1994 \{published data only\}}

Ekbom T, Lindholm LH, Oden A, Dahlof B, Hansson L, Wester PO, et al. A 5-year prospective, observational study of the withdrawal of antihypertensive treatment in elderly people. Journal of Internal Medicine 1994;235(6):581-8.

\section{ENOS Trial Investigators 2006 \{published data only\}}

ENOS Trial Investigators. Glyceryl trinitrate vs. control, and continuing vs. stopping temporarily prior antihypertensive therapy, in acute stroke: rationale and design of the Efficacy of Nitric Oxide in Stroke (ENOS) trial. International Journal of Stroke 2006;1(4):245-9.

\section{Espeland 1999 \{published data only\}}

Espeland MA, Whelton PK, Kostis JB, Bahnson JL, Ettinger WH, Cutler JA, et al. Predictors and mediators of successful longterm withdrawal from antihypertensive medications. TONE Cooperative Research Group. Trial of Nonpharmacologic Interventions in the Elderly. Archives of Family Medicine 1999;8(3):228-36.

\section{Fagerberg 1992 \{published data only\}}

Fagerberg B, Wikstrand J, Berglund G, Hartford M, Ljungman S, Wendelhag I. Withdrawal of antihypertensive drug treatment: time-course for redevelopment of hypertension and effects upon left ventricular mass. Journal of Hypertension 1992;10(6):587-93. 
Fernandez 1982 \{published data only\}

Fernandez PG, Galway AB, Kim BK. Prolonged normotension following cessation of therapy in uncomplicated essential hypertension. Clinical \& Investigative Medicine 1982;5(1):31-7.

\section{Finnerty 1985 \{published data only\}}

Finnerty FA Jr. Step-down therapy for hypertension. Results of withdrawal from multiple drugs and from a single drug. Postgraduate Medicine 1985;77(7):78-85.

\section{Froom 1997 \{published data only\}}

Froom J, Trilling JS, Yeh SS, Gomolin IH, Filkin AM, Grimson RC. Withdrawal of antihypertensive medications. Journal of the American Board of Family Practice 1997;10(6):447-8.

Giles 1988 \{published data only\}

Giles TD, Sander GE, Roffidal L, Thomas MG, Mersch DP, Moyer RR, et al. Remission of mild to moderate hypertension after treatment with carteolol, a beta-adrenoceptor blocker with intrinsic sympathomimetic activity. Archives of Internal Medicine 1988;148(8):1725-8.

\section{Goldberg 1977 \{published data only\}}

Goldberg AD, Raftery EB, Wilkinson P. Blood pressure and heart rate and withdrawal of antihypertensive drugs. $B M J$ 1977;1(6071):1243-6.

\section{Grimm 1997 \{published data only\}}

Grimm RH Jr. Warning - the physician's clinical judgement can be hazardous to your health: withdrawing drugs in patients with high blood pressure. Journal of the American Board of Family Practice 1997;10(4):305-7.

\section{Guthrie 2002 \{published data only\}}

Guthrie R, Reeves RA. Omapatrilat provides long-term control of hypertension: a randomized trial of treatment withdrawal. Journal of Clinical Hypertension 2002; Vol. 4, issue 3:169-72.

\section{Hajjar 2013 \{published data only\}}

Hajjar I, Hart M, Wan S, Novak V. Safety and blood pressure trajectory of short-term withdrawal of antihypertensive medications in older adults: experience from a clinical trial sample. Journal of the American Society of Hypertension 2013;7(4):289-93.

\section{Hansen 1983 \{published data only\}}

Hansen AG, Jensen H, Laugesen LP, Petersen A. Withdrawal of antihypertensive drugs in the elderly. Acta Medica Scandinavica 1983;676:178-85.

\section{Hansen 1985 \{published data only\}}

Hansen AG, Laugesen LP, Petersen A, Jensen H. Withdrawal of antihypertensive drugs in elderly patients. Ugeskrift for Laeger 1985;147(9):777-80.

\section{Hearing 1999 \{published data only\}}

Hearing SD, Wesnes KA, Bowman CE. Beta blockers and cognitive function in elderly hypertensive patients: withdrawal and consequences of ACE inhibitor substitution. International Journal of Geriatric Psychopharmacology 1999;2(1):13-7.

\section{Ho 1994 \{published data only\}}

Ho GY, Blaufox MD, Wassertheil-Smoller S, Oberman A, Langford $\mathrm{H}$. Plasma renin predicts success of antihypertensive drug withdrawal. American Journal of Hypertension 1994;7(8):679-84.

\section{ISRCTN31208535 \{unpublished data only\}}

ISRCTN31208535. A clinical trial to test amlodipine as a new treatment for vascular dementia. www.isrctn.com/ ISRCTN31208535 Date first assigned: 15 April 2014.

\section{ISRCTN82856726 \{unpublished data only\}}

ISRCTN82856726. AFFECT WALES: a comparison between an optimised treatment protocol and standard care for the treatment of Vascular Dementia. www.isrctn.com/ ISRCTN82856726 Date first assigned: 11 March 2016.

ISRCTN93682878 \{unpublished data only\}

ISRCTN93682878. Reducing pathology in Alzheimer's Disease through Angiotensin TaRgetting - The RADAR Trial. www.isrctn.com/ISRCTN93682878 Date first assigned: 10 September 2013.

Iyer 2008 \{published data only\}

lyer S, Naganathan V, McLachlan AJ, Le Couteur DG. Medication withdrawal trials in people aged 65 years and older: a systematic review. Drugs \& Aging 2008;25(12):1021-31.

\section{Kostis 1998 \{published data only\}}

Kostis JB, Espeland MA, Appel L, Johnson KC, Pierce J, Wofford JL. Does withdrawal of antihypertensive medication increase the risk of cardiovascular events? Trial of Nonpharmacologic Interventions in the Elderly (TONE) Cooperative Research Group. American Journal of Cardiology 1998;82(12):1501-8.

\section{Kuramoto 1978 \{published data only\}}

Kuramoto K, Seki A, Matsushita S, Kuwajima I, Mifune J, Iwasaki T, et al. Blood pressure elevation after withdrawal of antihypertensive drugs in the aged. Nippon Ronen Igakkai Zasshi 1978;15(6):562-5.

\section{Langford 1984 \{published data only\}}

Langford HG, Blaufox MD, Oberman A, Hawkins CM, Curb JD, Cutter GR, et al. Return of hypertension after withdrawal of prolonged antihypertensive therapy, effect of weight loss, sodium reduction, and baseline factors. Transactions of the Association of American Physicians 1984;97:190-6.

\section{Langford 1985 \{published data only\}}

Langford HG, Blaufox MD, Oberman A, Hawkins CM, Curb JD, Cutter GR, et al. Dietary therapy slows the return of hypertension after stopping prolonged medication. JAMA 1985;253(5):657-64.

\section{Maland 1983 \{published data only\}}

Maland LJ, Lutz LJ, Castle CH. Effects of withdrawing diuretic therapy on blood pressure in mild hypertension. Hypertension 1983;5(4):539-44. 
Maling 1979 \{published data only\}

Maling TJ, Dollery CT. Changes in blood pressure, heart rate, and plasma noradrenaline concentration after sudden withdrawal of propranolol. BMJ 1979;2(6186):366-7.

\section{Mehta 1994 \{published data only\}}

Mehta JL, Lopez LM. A double-blind evaluation of amlodipine in patients with chronic, stable angina: sustained efficacy and lack of "withdrawal phenomenon" upon abrupt discontinuation. Clinical Cardiology 1994;17(9 Suppl 3):III17-22.

\section{Middeke 1990 \{published data only\}}

Middeke M, Richter WO, Schwandt P, Beck B, Holzgreve H. Normalization of lipid metabolism after withdrawal from antihypertensive long-term therapy with beta blockers and diuretics. Arteriosclerosis 1990;10(1):145-7.

\section{Nedogoda 2012 \{published data only\}}

Nedogoda SV, Statsenko ME, Turkina SV, Tyshchenko IA, Poletaeva LV, Tsoma VV. Mildronate effects on cognitive function in elderly patients with arterial hypertension. Cardiovascular Therapy and Prevention 2012;11(5):33-8.

\section{Olsson 1986 \{published data only\}}

Olsson G, Hjemdahl P, Rehnqvist N. Cardiovascular reactivity to mental stress during gradual withdrawal of chronic postinfarction treatment with metoprolol. European Heart Journal 1986;7(9):765-72.

\section{Peart 1986 \{published data only\}}

Peart S, Barnes GR, Broughton PMG, Dollery CT, Green KG, Hudson MF, et al. Course of blood pressure in mild hypertensives after withdrawal of long term antihypertensive treatment. Medical Research Council Working Party on Mild Hypertension. BMJ 1986;293(6553):988-92.

\section{Pflugfelder 1993 \{published data only\}}

Pflugfelder PW, Baird MG, Tonkon MJ, DiBianco R, Pitt B. Clinical consequences of angiotensin-converting enzyme inhibitor withdrawal in chronic heart failure: a double-blind, placebocontrolled study of quinapril. The Quinapril Heart Failure Trial Investigators. Journal of the American College of Cardiology 1993;22(6):1557-63.

\section{PROGRESS Management Committee 1996 \{published data only\}} PROGRESS Management Committee. Blood pressure lowering for the secondary prevention of stroke: rationale and design for PROGRESS. Journal of Hypertension 1996; Vol. 14, issue 2:S41-5.

\section{Ruoff 1986 \{published data only\}}

Ruoff G. Effect of withdrawal of terazosin therapy in patients with hypertension. American Journal of Medicine 1986;80(5B):35-41.

\section{Sever 1991 \{published data only\}}

Sever PS, Poulter NR, McG Thom S, Sunman W. Withdrawing antihypertensive treatment. BMJ 1991;303(6803):643-5.

\section{Szecsi 1982 \{published data only\}}

Szecsi E, Kohlschutter S, Schiess W, Lang E. Abrupt withdrawal of pindolol or metoprolol after chronic therapy. British Journal of Clinical Pharmacology 1982;13(Suppl 2):353S-7S.

\section{Takata 1992 \{published data only\}}

Takata Y, Yoshizumi T, Ito Y, Ueno M, Tsukashima A, Iwase M, et al. Comparison of withdrawing antihypertensive therapy between diuretics and angiotensin converting enzyme inhibitors in essential hypertensives. American Heart Journal 1992;124(6):1574-80.

\section{Thaler 1993 \{published data only\}}

Thaler L, Wassertheil-Smoller S, Blaufox MD, Oberman A, Langford HG. Effect of withdrawal of antihypertensive drug on depressive mood. American Journal of Hypertension 1993;6(12):1055-62.

\section{Thomas 2006 \{published data only\}}

Thomas D, Lees K, Hextall F J, Skene A, Pocock S, Wardlaw JM, et al. Glyceryl trinitrate vs. control, and continuing vs. stopping temporarily prior antihypertensive therapy, in acute stroke: rationale and design of the Efficacy of Nitric Oxide in Stroke (ENOS) trial (ISRCTN99414122). International Journal of Stroke 2006;1(4):245-9.

\section{van Wel 2011 \{published data only\}}

van Wel JH, Kuypers KP, Theunissen EL, Bosker WM, Bakker K, Ramaekers JG. Blockade of 5-HT2 receptor selectively prevents MDMA-induced verbal memory impairment. Neuropsychopharmacology 2011;36(9):1932-9.

\section{Vaur 1998 \{published data only\}}

Vaur L, Bobrie G, Dutrey-Dupagne C, Dubroca I, Vaisse B, d'Yvoire MB, et al. Short-term effects of withdrawing angiotensin converting enzyme inhibitor therapy on home selfmeasured blood pressure in hypertensive patients. American Journal of Hypertension 1998;11(2):165-73.

Walma 1997 \{published data only\}

Walma EP, Hoes AW, van Dooren C, Prins A, van der Does E. Withdrawal of long-term diuretic medication in elderly patients: a double blind randomised trial. BMJ 1997;315(7106):464-8.

\section{Wan 2010 \{published data only\}}

Wan SH, Hart M, Hajjar I. Safety, feasibility, and advantages of tapering antihypertensive agents in older adults preparing for enrollment in a cognitive clinical trial. Neurology 2010, (9):A144.

\section{Additional references}

\section{Alrawi 2013}

Alrawi YA, Panerai RB, Myint PK, Potter JF. Pharmacological blood pressure lowering in the older hypertensive patients may lead to cognitive impairment by altering neurovascular coupling. Medical Hypotheses 2013;80(3):303-7. 


\section{Anathhanam 2012}

Anathhanam S, Powis RA, Cracknell AL, Robson J. Impact of prescribed medications on patient safety in older people. Therapeutic Advances in Drug Safety 2012;3(4):165-74.

\section{Bath 2014}

Bath PM, Houlton A, Woodhouse L, Sprigg N, Wardlaw J, Pocock S, ENOS Trialists. Statistical analysis plan for the 'Efficacy of Nitric Oxide in Stroke' (ENOS) trial. International Journal of Stroke 2014;9(3):372-4.

\section{Beckett 2012}

Beckett N, Peters R, Tuomilehto J, Swift C, Sever P, Potter J, et al. HYVET Study Group. Immediate and late benefits of treating very elderly people with hypertension: results from active treatment extension to Hypertension in the Very Elderly randomised controlled trial. BMJ 2012;344:d7541.

\section{Beishon 2014}

Beishon LC, Harrison JK, Harwood RH, Robinson TG, Gladman JR, Conroy SP. The evidence for treating hypertension in older people with dementia: a systematic review. Journal of Human Hypertension 2014;28(5):283-7.

\section{Benetos 2015a}

Benetos A, Labat C, Rossignol P, Fay R, Rolland Y, Valbusa F, et al. Treatment with multiple blood pressure medications, achieved blood pressure, and mortality in older nursing home residents: the PARTAGE study. JAMA Internal Medicine 2015; Vol. 175, issue 6:989-95.

\section{Bruscoli 2004}

Bruscoli $\mathrm{M}$, Lovestone $\mathrm{S}$. Is $\mathrm{MCl}$ really just early dementia? A systematic review of conversion studies. International Psychogeriatrics 2004;16(2):129-40.

\section{Chow 2013}

Chow CK, Teo KK, Rangarajan S, Islam S, Gupta R, Avezum A, et al. Prevalence, awareness, treatment, and control of hypertension in rural and urban communities in high-, middle-, and low-income countries. JAMA 2013;310(9):959-68.

\section{Cohen 2011}

Cohen DL, Townsend RR. Update on pathophysiology and treatment of hypertension in the elderly. Current Hypertension Reports 2011;13(5):330-7.

\section{den Abeelen 2014}

den Abeelen AS, Lagro J, van Beek AH, Claassen JA. Impaired cerebral autoregulation and vasomotor reactivity in sporadic Alzheimer's disease. Current Alzheimer Research 2014;11(1):11-7.

\section{deprescribing.org}

Farrell B, Tannenbaum C. Canadian Deprescribing Network (CaDeN). www.deprescribing.org (accessed 25 October 2016).

\section{Di Bari 2001}

Di Bari M, Pahor M, Franse LV, Shorr RI, Wan JY, Ferrucci L, et al. Dementia and disability outcomes in large hypertension trials: lessons learned from the systolic hypertension in the elderly program (SHEP) trial. American Journal of Epidemiology 2001;153(1):72-8.

\section{Ferri 2005}

Ferri CP, Prince M, Brayne C, Brodaty H, Fratiglioni L, Ganguli M, et al. Global prevalence of dementia: a Delphi consensus study. Lancet 2005;366(9503):2112-7.

\section{Folstein 1975}

Folstein MF, Folstein SE, McHugh PR. "Mini-mental state". A practical method for grading the cognitive state of patients for the clinician. Journal of Psychiatric Research 1975;12(3):189-98.

\section{Gauthier 2006}

Gauthier S, Reisberg B, Zaudig M, Petersen RC, Ritchie K, Broich $\mathrm{K}$, et al. Mild cognitive impairment. Lancet 2006;367(9518):1262-70.

\section{GRADEproGDT 2015 [Computer program]}

GRADE Working Group, McMaster University. GRADEproGDT. Hamilton (ON): GRADE Working Group, McMaster University, 2015.

\section{Higgins 2011}

Higgins JPT, Green S (editors). Cochrane Handbook for Systematic Reviews of Interventions Version 5.1.0 (updated March 2011). The Cochrane Collaboration, 2011. Available from www.cochrane-handbook.org.

\section{ICHOM 2016}

International Consortium for Health Outcomes Measurement (ICHOM): Who are we? 2016. www.ichom.org/who-we-are/ (accessed 25 October 2016).

\section{Karachalios 2005}

Karachalios GN, Charalabopoulos A, Papalimnenou V, Kiortsis D, Dimmicco P, Kostoula OK, et al. Withdrawal syndrome following cessation of antihypertensive drug therapy. International Journal of Clinical Practice 2005;59(5):562-70.

\section{Kennelly 2009}

Kennelly SP, Lawlor BA, Kenny RA. Blood pressure and the risk for dementia: a double edged sword. Ageing Research Reviews 2009;8(2):61-70.

\section{Khachaturian 2006}

Khachaturian AS, Zandi PP, Lyketsos CG, Hayden KM, Skoog I, Norton MC, et al. Antihypertensive medication use and incident Alzheimer disease: the Cache County Study. Archives of Neurology 2006;63:686-92.

\section{Law 2009}

Law MR, Morris JK, Wald NJ. Use of blood pressure lowering drugs in the prevention of cardiovascular disease: metaanalysis of 147 randomised trials in the context of expectations from prospective epidemiological studies. BMJ 2009;338:b1665.

\section{Levi Marpillat 2013}

Levi Marpillat N, Macquin-Mavier I, Tropeano Al, BachoudLevi AC, Maison P. Antihypertensive classes, cognitive decline 
and incidence of dementia: a network meta-analysis. Journal of Hypertension 2013;31(6):1073-82.

\section{Lewington 2002}

Lewington S, Clarke R, Qizilbash N, Peto R, Collins R. Agespecific relevance of usual blood pressure to vascular mortality: a meta-analysis of individual data for one million adults in 61 prospective studies. Lancet 2002;360(9349):1903-13.

\section{Markus 2004}

Markus HS. Cerebral perfusion and stroke. Journal of Neurology, Neurosurgery and Psychiatry 2004;75:353-61.

\section{Matthews 2016}

Matthews FE, Stephan BC, Robinson L, Jagger C, Barnes LE, Arthur A, et al. A two decade dementia incidence comparison from the Cognitive Function and Ageing Studies I and II. Nature Communications 2016;7:11398.

\section{Moher 2009}

Moher D, Liberati A, Tetzlaff J, Altman DG, The PRISMA Group. Preferred reporting items for systematic reviews and metaanalyses: the PRISMA Statement. BMJ 2009;339:2535.

\section{Mossello 2015}

Mossello E, Pieraccioli M, Nesti N, Bulgaresi M, Lorenzi C, Caleri V, et al. Effects of low blood pressure in cognitively impaired elderly patients treated with antihypertensive drugs. JAMA Internal Medicine 2015;175(4):578-85.

\section{Musini 2009}

Musini VM, Tejani AM, Bassett K, Wright JM. Pharmacotherapy for hypertension in the elderly. Cochrane Database of Systematic Reviews 2009, Issue 4. [DOI: 10.1002/14651858.CD000028.pub2]

\section{Nasreddine 2005}

Nasreddine ZS, Phillips NA, Bedirian V, Charbonneau S, Whitehead V, Collin I, et al. The Montreal Cognitive Assessment, MoCA: a brief screening tool for mild cognitive impairment. Journal of the American Geriatrics Society 2005;53(4):695-9.

\section{Ni Chroinin 2015}

Ni Chroinin D, Ni Chroinin C, Beveridge A. Factors influencing deprescribing habits among geriatricians. Age and Ageing 2015;44(4):704-8.

\section{Nilsson 2007}

Nilsson SE, Read S, Berg S, Johansson B, Melander A, Lindblad U. Low systolic blood pressure is associated with impaired cognitive function in the oldest old: longitudinal observations in a population-based sample 80 years and older. Aging Clinical and Experimental Research 2007;19(1):41-7.

\section{Norton 2014}

Norton S, Matthews FE, Barnes DE, Yaffe K, Brayne C. Potential for primary prevention of Alzheimer's disease: an analysis of population-based data. Lancet Neurology 2014;13(8):788-94.

\section{Opondo 2012}

Opondo D, Eslami S, Visscher S, de Rooij SE, Verheij R, Korevaar JC, et al. Inappropriateness of medication prescriptions to elderly patients in the primary care setting: a systematic review. PLoS One 2012;7(8):e43617.

\section{Peters 2008}

Peters R, Beckett N, Forette F, Tuomilehto J, Clarke R, Ritchie C, et al. Incident dementia and blood pressure lowering in the Hypertension in the Very Elderly Trial cognitive function assessment (HYVET-COG): a double-blind, placebo controlled trial. Lancet Neurology 2008;7(8):683-9.

\section{Qiu 2009}

Qiu C, Winblad B, Fratiglioni L. Low diastolic pressure and risk of dementia in very old people: a longitudinal study. Dementia and Geriatric Cognitive Disorders 2009;28(3):213-9.

\section{Qui 2003}

Qiu C, Winblad B, Fastbom J, Fratiglioni L. Combined effects of APOE genotype, blood pressure and antihypertensive drug use on incident AD. Neurology 2003;61:655-60.

\section{Reeve 2013}

Reeve E, To J, Hendrix I, Shakib S, Roberts MS, Wiese MD. Patient barriers to and enablers of deprescribing: a systematic review. Drugs \& Aging 2013;30(10):793-807.

\section{RevMan 2014 [Computer program]}

The Nordic Cochrane Centre, The Cochrane Collaboration. Review Manager (RevMan). Version 5.3. Copenhagen: The Nordic Cochrane Centre, The Cochrane Collaboration, 2014.

\section{Schünemann 2011a}

Schünemann HJ, Oxman AD, Higgins JPT, Vist GE, Glasziou P, Guyatt GH. Chapter 11: Presenting results and 'Summary of findings' tables. In: Higgins JPT, Green S (editors). Cochrane Handbook for Systematic Reviews of Interventions Version 5.1.0 (updated March 2011). The Cochrane Collaboration, 2011. Available from www.cochrane-handbook.org.

\section{Schünemann 2011b}

Schünemann HJ, Oxman AD, Vist GE, Higgins JPT, Deeks JJ, Glasziou P, et al. Chapter 12: Interpreting results and drawing conclusions. In: Higgins JPT, Green S (editors). Cochrane Handbook for Systematic Reviews of Interventions Version 5.1.0 (updated March 2011). The Cochrane Collaboration, 2011. Available from www.cochrane-handbook.org.

\section{Scott 2015}

Scott IA, Himer SN, Reeve E, Potter K, Le Couteur D, Rigby D, et al. Reducing inappropriate polypharmacy: the process of deprescribing. JAMA Internal Medicine 2015;175(5):827-34.

\section{Shah 2009}

Shah K, Qureshi SU, Johnson M, Parikh N, Schulz PE, Kunik ME. Does use of antihypertensive drugs affect the incidence or progression of dementia? A systematic review. American Journal of Geriatric Pharmacotherapy 2009;7(5):250-61. 


\section{Skoog 1996}

Skoog I, Lernfelt B, Landahl S, Palmertz B, Andreasson LA, Nilsson $L$, et al. 15-year longitudinal study of blood pressure and dementia. Lancet 1996;347(9009):1141-5.

\section{Skoog 2005}

Skoog I, Lithell H, Hansson L, Elmfeldt D, Hofman A, Olofsson B, et al. Effect of baseline cognitive function and antihypertensive treatment on cognitive and cardiovascular outcomes: Study on COgnition and Prognosis in the Elderly (SCOPE). American Journal of Hypertension 2005;18(8):1052-9.

\section{Stafford 2011}

Stafford AC, Alswayan MS, Tenni PC. Inappropriate prescribing in older residents of Australian care homes. Journal of Clinical Pharmacology and Therapeutics 2011;36(1):33-44.

\section{Tinetti 2014}

Tinetti ME, Han L, Lee DS, McAvay GJ, Peduzzi P, Gross CP, et al. Antihypertensive medications and serious fall injuries in a nationally representative sample of older adults. JAMA Internal Medicine 2014;174(4):588-95.

\section{Tjia 2013}

Tjia J, Velten SJ, Parsons C, Valluri S, Briesacher BA. Studies to reduce unnecessary medication use in frail older adults: a systematic review. Drugs \& Ageing 2013;30(5):285-307.

\section{Tjia 2014}

Tjia J, Briesacher BA, Peterson D, Liu Q, Andrade SE, Mitchell SL. Use of medications of questionable benefit in advanced dementia. JAMA Internal Medicine 2014;174(11):1763-71.

\section{Tully 2016}

Tully PJ, Hanon O, Cosh S, Tzourio C. Diuretic antihypertensive drugs and incident dementia risk: a systematic review, metaanalysis and meta-regression of prospective studies. Journal of Hypertension 2016;34(6):1027-35.

\section{Tzourio 2003}

Tzourio C, Anderson C, Chapman N, Woodward M, Neal B, MacMahon S, et al. Effects of blood pressure lowering with perindopril and indapamide therapy on dementia and cognitive decline in patients with cerebrovascular disease. Archives of Internal Medicine 2003;163(9):1069-75.

\section{van der Wardt 2016}

van der Wardt. Hypertension in dementia - feasibility study. www.ukctg.nihr.ac.uk/trials/trial-details/trial-details? trialld=30840 (accessed 16 June 2016).

\section{WHO 2015}

World Health Organization. Dementia fact sheet No. 362. www.who.int/mediacentre/factsheets/fs362/en/ (accessed March 2015).

\section{Yasar 2005}

Yasar S, Corrada M, Brookmeyer R, Kawas C. Calcium channel blockers and risk of AD: the Baltimore Longitudinal Study of Aging. Neurobiology of Aging 2005;26:157-63.

\section{Zhuang 2016}

Zhuang S, Wang HF, Li J, Wang HY, Wang X, Xing CM. Reninangiotensin system blockade use and risks of cognitive decline and dementia: a meta-analysis. Neuroscience Letters 2016;15(624):53-61.

* Indicates the major publication for the study

\section{CHARACTERISTICS OF STUDIES}

Characteristics of included studies [ordered by study ID]

\section{Bath 2015}

Design: randomised controlled parallel group trial

Date of study: 20 July 2001 to 14 October 2013

Sample size calculation: yes, needed 1750 for primary outcome

Inclusion criteria: adults with a clinical stroke syndrome with limb weakness lasting at least 1 hour (i.e. not likely to be a transient ischaemic attack), residual limb weakness at the time of enrolment, with onset $<48$ hours, conscious (Glasgow Coma Scale $>8$ ), systolic blood pressure in range $140 \mathrm{mmHg}$ to 220 $\mathrm{mmHg}$ inclusive on the basis of at least 1 of the 3 baseline prerandomisation measures, independent prior to stroke (premorbid $\mathrm{mRS}<2$ ) and capable of a meaningful consent, or assent from a relative or carer if the person was unable to give meaningful consent (e.g. in cases of dysphasia, confusion or reduced conscious level).

Exclusion criteria: a definite need to start (e.g. for thrombolysis), continue or stop blood pressure lowering drugs; need for, or contraindication to, glyceryl trinitrate; coma (Glasgow coma scale score < 8); pure sensory stroke; isolated dysphasia; preceding moderate or severe dependency (mRS score 3 to 5); confounding neurological or psychiatric disease; a disorder mimicking stroke (e.g. hypoglycaemia, Todd's paresis); liver dysfunction (international normalised ratio $>1.5$, aminotransferase $>3$ 
Bath 2015 (Continued)

times normal concentrations) or renal dysfunction (creatinine $>3$ times normal concentrations); severe concomitant medical disorder; pregnancy or breastfeeding; previous participation in the ENOS trial; planned surgical intervention or participation in another trial within 2 weeks.

Number in study: 2097
Country: international multicentre
Setting: acute hospitalisation for stroke
Age mean (SD): 73 (11) years
Sex: intervention $52 \%$ men; control 50\% men
Comorbidity: assessed and comparable at baseline
Level of education: not reported
Dementia: cognitive status not assessed at baseline

Interventions

Intervention: withdrawal of pre-existing antihypertensive medications for 7 days following stroke

Control: continue pre-existing antihypertensive medications following stroke

\begin{tabular}{ll}
\hline Outcomes & Measured at 90 days: \\
& - t-MMSE \\
& TICS-M \\
& blood pressure \\
& mortality \\
& adherence to withdrawal \\
\hline Notes & Funding source: UK Medical Research Council \\
& Declaration of interest: "We declare no competing interests"
\end{tabular}

\section{Risk of bias}

\begin{tabular}{|c|c|c|}
\hline Bias & Authors' judgement & Support for judgement \\
\hline $\begin{array}{l}\text { Random sequence genera- } \\
\text { tion (selection bias) }\end{array}$ & Low risk & $\begin{array}{l}\text { Comment: they used stratification and minimisation to ensure that the groups } \\
\text { were balanced for prognostic factors, and the random element reduced pre- } \\
\text { dictability. }\end{array}$ \\
\hline $\begin{array}{l}\text { Allocation concealment } \\
\text { (selection bias) }\end{array}$ & Low risk & Quote: "Central computer based system." \\
\hline $\begin{array}{l}\text { Blinding of participants } \\
\text { and personnel (perfor- } \\
\text { mance bias) } \\
\text { All outcomes }\end{array}$ & High risk & $\begin{array}{l}\text { Comment: not blinded for participant or personnel if the antihypertensive } \\
\text { medication was stopped. }\end{array}$ \\
\hline $\begin{array}{l}\text { Blinding of outcome as- } \\
\text { sessment (detection bias) } \\
\text { All outcomes }\end{array}$ & Low risk & $\begin{array}{l}\text { Quote: "The coordinating centre of each country (masked to treatment alloca- } \\
\text { tion) did the final follow-up centrally at } 90 \text { days by telephone." }\end{array}$ \\
\hline $\begin{array}{l}\text { Incomplete outcome data } \\
\text { (attrition bias) } \\
\text { All outcomes }\end{array}$ & Low risk & $\begin{array}{l}\text { Comment: they applied an intention-to-treat analysis. For primary outcome } \\
\text { of this review: } 1778 \text { participants alive at } 90 \text { days' follow-up and so eligible for } \\
\text { cognitive assessment. Results table reported t-MMSE data for } 1272 \text { partic- }\end{array}$ \\
\hline
\end{tabular}


Bath 2015 (Continued)

ipants and TICS-M data for 1179 participants - no explanation provided for missing assessment data.

\begin{tabular}{lll}
\hline $\begin{array}{l}\text { Selective reporting (re- } \\
\text { porting bias) }\end{array}$ & Low risk & Comment: outcomes reported as described in published protocol. \\
\hline Other bias & Low risk & Comment: none were identified. \\
\hline
\end{tabular}

\section{Moonen 2015}

Design: randomised controlled parallel group trial
Date of study: 26 June 2011 to 23 August 2013
Sample size calculation: yes, 400 participants required for primary outcome
Inclusion criteria: aged $\geq 75$ years, used antihypertensive treatment, systolic blood pressure $\leq 160 \mathrm{~mm}$
$\mathrm{Hg}$ and had an MMSE score of 21 to 27.
Exclusion criteria: a clinical diagnosis of dementia, use of antihypertensives for reasons other than hy-
pertension, current angina pectoris, cardiac arrhythmia, heart failure, myocardial infarction or a coro-
nary reperfusion procedure < 3 years ago, a history of stroke or transient ischaemic attack or a limited
life expectancy.

\begin{tabular}{|c|c|}
\hline \multirow[t]{8}{*}{ Participants } & Number in study: 393 \\
\hline & Country: the Netherlands \\
\hline & Setting: community primary care \\
\hline & Age mean (SD): intervention 81.1 (4.3) years; control 81.5 (4.6) years \\
\hline & Sex: intervention $77 \%$ men; control $70 \%$ men \\
\hline & Comorbidity: assessed and comparable at baseline \\
\hline & Level of education: assessed and comparable at baseline \\
\hline & Dementia: people with existing dementia were excluded \\
\hline \multirow[t]{2}{*}{ Interventions } & $\begin{array}{l}\text { Intervention: discontinuation of antihypertensive medications over a 6-week period after randomisa- } \\
\text { tion using a withdrawal algorithm with outcome assessment at } 16 \text { weeks }\end{array}$ \\
\hline & $\begin{array}{l}\text { Control: blood pressure medication continued. Blood pressure recorded at } 6 \text { and } 10 \text { weeks postran- } \\
\text { domisation and at } 16 \text { weeks }\end{array}$ \\
\hline \multirow[t]{7}{*}{ Outcomes } & Measured after 16 weeks: \\
\hline & $\begin{array}{l}\text { Overall cognition (compound score): computed if } 5 \text { of the following } 6 \text { tests were available: Stroop- } \\
\text { Colour Word Test and Trail Making Test for executive functioning, 15-Word Verbal Learning Test and } \\
\text { Visual Association Test for (immediate and delayed) verbal and picture memory and Letter-Digit Sub- } \\
\text { stitution Test for psychomotor speed }\end{array}$ \\
\hline & - MMSE for global cognitive functioning \\
\hline & - Blood pressure \\
\hline & - Mortality \\
\hline & - Adherence to withdrawal \\
\hline & - Serious adverse events (including myocardial infarction, hospitalisations) \\
\hline
\end{tabular}


Moonen 2015 (Continued)

Notes

Funding source: this study was supported by a grant from Program Priority Medicines for the Elderly, the Netherlands Organization for Health Research and Development (Project 113101003)

Declaration of interest: "None reported"

\section{Risk of bias}

\begin{tabular}{lll}
\hline Bias & Authors' judgement & Support for judgement \\
\hline $\begin{array}{l}\text { Random sequence genera- } \\
\text { tion (selection bias) }\end{array}$ & Low risk & $\begin{array}{l}\text { Quote: "Participants were randomly assigned, in a 1:1 ratio, to parallel discon- } \\
\text { tinuation (intervention group) or continuation (control group) of anti- hyper- } \\
\text { tensive treatment. }\end{array}$ \\
& $\begin{array}{l}\text { The allocation was generated by a central computerized randomisation proce- } \\
\text { dure in a 1:1 ratio in stratified block randomisation." }\end{array}$
\end{tabular}

\begin{tabular}{ll}
\hline $\begin{array}{l}\text { Allocation concealment } \\
\text { (selection bias) }\end{array}$ & Low risk \\
& $\begin{array}{l}\text { Quote: "Stratified block randomisation was used (with block sizes of } 4 \text { per gen- } \\
\text { eral practice) to ensure that intervention and control participants were equally } \\
\text { distributed within general practices. }\end{array}$
\end{tabular}

Concealment of treatment allocation was ensured by a central computerized randomisation procedure."

\begin{tabular}{ll}
\hline $\begin{array}{l}\text { Blinding of participants } \\
\text { and personnel (perfor- }\end{array}$ & High risk
\end{tabular}

mance bias)

All outcomes

Blinding of outcome as- Low risk sessment (detection bias)

All outcomes

Quote: "At baseline and at the follow-up 16 weeks after randomisation, blood pressure was measured and cognitive, psychological, and general daily functioning were assessed by trained blinded research personnel during home visits.

Study outcomes ... were assessed in a standardized manner by research personnel masked to the allocated intervention."

\begin{tabular}{ll}
\hline $\begin{array}{l}\text { Incomplete outcome data } \\
\text { (attrition bias) }\end{array}$ & Low risk \\
All outcomes & $\begin{array}{l}\text { Comment: intention-to-treat analysis in both groups. However, cognitive as- } \\
\text { sessment data missing for primary outcome without explanation provided. }\end{array}$
\end{tabular}

\begin{tabular}{lll}
\hline $\begin{array}{l}\text { Selective reporting (re- } \\
\text { porting bias) }\end{array}$ & Low risk & Comment: outcomes reported as described in published protocol. \\
\hline Other bias & Low risk & Comment: no evidence of other bias. \\
\hline
\end{tabular}

ENOS: Efficacy of Nitric Oxide in Stroke; MMSE: Mini-Mental State Examination; mRS: modified Rankin Scale; SD: standard deviation; tMMSE: Telephone-Mini Mental State Examination; TICS-M: Modified Telephone Interview for Cognitive Status.

Characteristics of excluded studies [ordered by study ID]

\begin{tabular}{ll}
\hline Study & Reason for exclusion \\
\hline Aberg 1989 & Not an RCT \\
\hline ADVANCE 2001 & Study protocol, study not included \\
\hline Al-Qassab 1988 & No cognitive outcomes \\
\hline \hline
\end{tabular}




\begin{tabular}{|c|c|}
\hline Study & Reason for exclusion \\
\hline Alabaster 1983 & Not an RCT \\
\hline Alderman 1985 & Not an RCT \\
\hline Alderman 1986 & Not an RCT \\
\hline Andersen 2003 & No cognitive outcomes \\
\hline Andersen 2009 & No cognitive outcomes \\
\hline Anonymous 1975 & Not an RCT \\
\hline Appel 1995 & Study protocol, study not included \\
\hline Ashford 1986 & Not an RCT \\
\hline Aylett 1994 & Not an RCT \\
\hline Aylett 1999 & Not an RCT \\
\hline Benetos 2015b & Not an RCT \\
\hline Bevan 1993 & No cognitive outcomes \\
\hline Blaufox 1984 & No cognitive outcomes \\
\hline Blom 1993 & No cognitive outcomes \\
\hline Bouzas-Mosquera 2008 & Not an RCT \\
\hline Boyle 1979 & Not an RCT \\
\hline Braunschweig 2002 & Not an RCT \\
\hline Brundin 1976 & Not an RCT \\
\hline Burton 1991 & Not an RCT \\
\hline Böhm 2015 & Wrong comparator, no withdrawal of an antihypertensive \\
\hline Charalabopoulos 2005 & Not an RCT \\
\hline Choulerton 2010 & Not an RCT \\
\hline Chrysant 1978 & Not an RCT \\
\hline Cooper 1988 & Not an RCT \\
\hline Croft 1986 & No cognitive outcomes \\
\hline Cullhed 1976 & Not an RCT \\
\hline Danielson 1981 & Not an RCT \\
\hline Danilevicius 1977 & Not an RCT \\
\hline
\end{tabular}




\begin{tabular}{|c|c|}
\hline Study & Reason for exclusion \\
\hline Deckert 1994 & Not an RCT \\
\hline Düsing 2012 & No cognitive outcomes \\
\hline Ekbom 1994 & Not an RCT \\
\hline ENOS Trial Investigators 2006 & Study protocol, study included \\
\hline Espeland 1999 & No cognitive outcomes \\
\hline Fagerberg 1992 & Not an RCT \\
\hline Fernandez 1982 & Not an RCT \\
\hline Finnerty 1985 & Not an RCT \\
\hline Froom 1997 & Not an RCT \\
\hline Giles 1988 & No cognitive outcomes \\
\hline Goldberg 1977 & Not an RCT \\
\hline Grimm 1997 & Not an RCT \\
\hline Guthrie 2002 & No cognitive outcomes \\
\hline Hajjar 2013 & Not an RCT \\
\hline Hansen 1983 & Not an RCT \\
\hline Hansen 1985 & Not an RCT \\
\hline Hearing 1999 & $\begin{array}{l}\text { All participants were originally taking atenolol and the intervention group withdrew } \\
\text { the atenolol, but received an angiotensin converting enzyme inhibitor instead. Since } \\
\text { the antihypertensive treatment was replaced with another antihypertensive treat- } \\
\text { ment, we found this intervention not suitable for this review. }\end{array}$ \\
\hline Ho 1994 & No cognitive outcomes \\
\hline ISRCTN31208535 & $\begin{array}{l}\text { Wrong intervention, there is no antihypertensive treatment withdrawn. Still in recruit- } \\
\text { ment phase. }\end{array}$ \\
\hline ISRCTN82856726 & $\begin{array}{l}\text { Wrong intervention, there is no antihypertensive treatment withdrawn. Still in recruit- } \\
\text { ment phase. }\end{array}$ \\
\hline ISRCTN93682878 & $\begin{array}{l}\text { Wrong intervention, there is no antihypertensive treatment withdrawn. Still in recruit- } \\
\text { ment phase. }\end{array}$ \\
\hline lyer 2008 & Not an RCT \\
\hline Kostis 1998 & No cognitive outcomes \\
\hline Kuramoto 1978 & Not an RCT \\
\hline Langford 1984 & No cognitive outcomes \\
\hline
\end{tabular}




\begin{tabular}{|c|c|}
\hline Study & Reason for exclusion \\
\hline Langford 1985 & No cognitive outcomes \\
\hline Maland 1983 & No cognitive outcomes \\
\hline Maling 1979 & Not an RCT \\
\hline Mehta 1994 & No cognitive outcomes \\
\hline Middeke 1990 & No cognitive outcomes \\
\hline Nedogoda 2012 & Wrong comparator, there is no withdrawal of antihypertensive treatment. \\
\hline Olsson 1986 & No cognitive outcomes \\
\hline Peart 1986 & No cognitive outcomes \\
\hline Pflugfelder 1993 & No cognitive outcomes \\
\hline PROGRESS Management Committee 1996 & Study protocol, study not included \\
\hline Ruoff 1986 & No cognitive outcomes \\
\hline Sever 1991 & Not an RCT \\
\hline Szecsi 1982 & No cognitive outcomes \\
\hline Takata 1992 & No cognitive outcomes \\
\hline Thaler 1993 & No cognitive outcomes \\
\hline Thomas 2006 & Study protocol, study not included \\
\hline van Wel 2011 & No withdrawal of antihypertensive treatment \\
\hline Vaur 1998 & No cognitive outcomes \\
\hline Walma 1997 & No cognitive outcomes \\
\hline Wan 2010 & Not an RCT \\
\hline
\end{tabular}

$\mathrm{RCT}$ : randomised controlled trial.

\section{DATA AND ANALYSES}

Comparison 1. Cognitive function (at 90 days)

\begin{tabular}{lllll}
\hline Outcome or subgroup title & No. of studies & $\begin{array}{l}\text { No. of partici- } \\
\text { pants }\end{array}$ & Statistical method & Effect size \\
\hline $\begin{array}{l}1 \text { Telephone Mini-Mental State Exami- } \\
\text { nation score }\end{array}$ & 1 & & $\begin{array}{l}\text { Mean Difference (IV, Random, } \\
95 \% \mathrm{Cl})\end{array}$ & Subtotals only \\
\hline
\end{tabular}




\begin{tabular}{lllll}
\hline Outcome or subgroup title & No. of studies & $\begin{array}{l}\text { No. of partici- } \\
\text { pants }\end{array}$ & Statistical method & Effect size \\
\hline $\begin{array}{l}\text { 2 Modified Telephone Interview for } \\
\text { Cognitive Status score }\end{array}$ & 1 & & $\begin{array}{l}\text { Mean Difference (IV, Random, } \\
95 \% \mathrm{Cl})\end{array}$ & Subtotals only \\
\hline
\end{tabular}

Analysis 1.1. Comparison 1 Cognitive function (at 90 days), Outcome 1 Telephone Mini-Mental State Examination score.

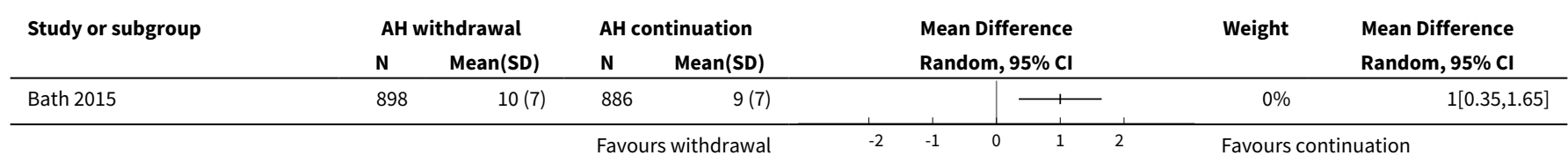

Analysis 1.2. Comparison 1 Cognitive function (at 90 days), Outcome 2 Modified Telephone Interview for Cognitive Status score.

\begin{tabular}{|c|c|c|c|c|c|c|c|}
\hline \multirow[t]{2}{*}{ Study or subgroup } & \multicolumn{2}{|c|}{ AH withdrawal } & \multicolumn{2}{|c|}{ AH continuation } & \multirow{2}{*}{$\begin{array}{l}\text { Mean Difference } \\
\text { Random, } 95 \% \mathrm{Cl}\end{array}$} & \multirow[t]{2}{*}{ Weight } & \multirow{2}{*}{$\begin{array}{l}\text { Mean Difference } \\
\text { Random, } 95 \% \mathrm{Cl}\end{array}$} \\
\hline & $\mathbf{N}$ & $\operatorname{Mean}(S D)$ & $\mathbf{N}$ & Mean(SD) & & & \\
\hline Bath 2015 & 898 & $21.1(15.1)$ & 886 & $19(15.2)$ & 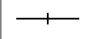 & $0 \%$ & $2.1[0.69,3.51]$ \\
\hline
\end{tabular}

\section{Comparison 2. Change in cognitive function (over 16 weeks)}

\begin{tabular}{|c|c|c|c|c|}
\hline Outcome or subgroup title & No. of studies & $\begin{array}{l}\text { No. of partici- } \\
\text { pants }\end{array}$ & Statistical method & Effect size \\
\hline 1 Composite score & 1 & & $\begin{array}{l}\text { Mean Difference (IV, Random, 95\% } \\
\mathrm{CI})\end{array}$ & Subtotals only \\
\hline $\begin{array}{l}2 \text { Mini-Mental State Examination } \\
\text { score }\end{array}$ & 1 & & $\begin{array}{l}\text { Mean Difference (IV, Random, 95\% } \\
\mathrm{CI} \text { ) }\end{array}$ & Subtotals only \\
\hline 3 Stroop Interference score & 1 & & $\begin{array}{l}\text { Mean Difference (IV, Random, 95\% } \\
\mathrm{CI} \text { ) }\end{array}$ & Subtotals only \\
\hline 4 Trail making test score & 1 & & $\begin{array}{l}\text { Mean Difference (IV, Random, 95\% } \\
\mathrm{CI})\end{array}$ & Subtotals only \\
\hline $\begin{array}{l}515 \text {-Word Verbal Learning Im- } \\
\text { mediate Recall score }\end{array}$ & 1 & & $\begin{array}{l}\text { Mean Difference (IV, Random, 95\% } \\
\mathrm{CI})\end{array}$ & Subtotals only \\
\hline $\begin{array}{l}615 \text {-Word Verbal Learning De- } \\
\text { layed Recall score }\end{array}$ & 1 & & $\begin{array}{l}\text { Mean Difference (IV, Random, 95\% } \\
\mathrm{CI})\end{array}$ & Subtotals only \\
\hline 7 Visual Association Test score & 1 & & $\begin{array}{l}\text { Mean Difference (IV, Random, 95\% } \\
\mathrm{CI} \text { ) }\end{array}$ & Subtotals only \\
\hline
\end{tabular}


Analysis 2.1. Comparison 2 Change in cognitive function (over 16 weeks), Outcome 1 Composite score.

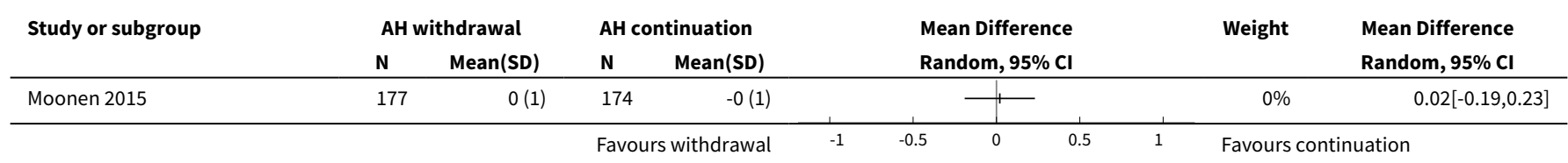

Analysis 2.2. Comparison 2 Change in cognitive function (over 16 weeks), Outcome 2 Mini-Mental State Examination score.

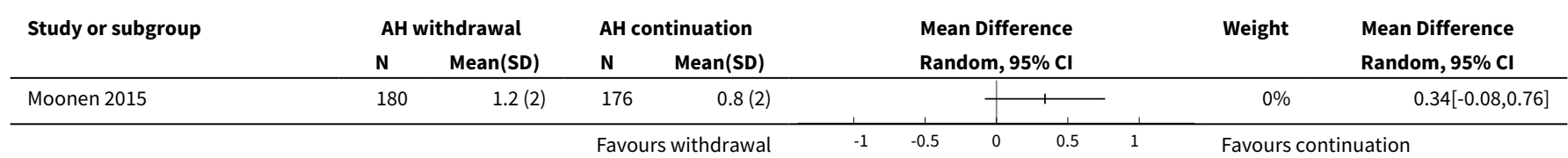

Analysis 2.3. Comparison 2 Change in cognitive function (over 16 weeks), Outcome 3 Stroop Interference score.

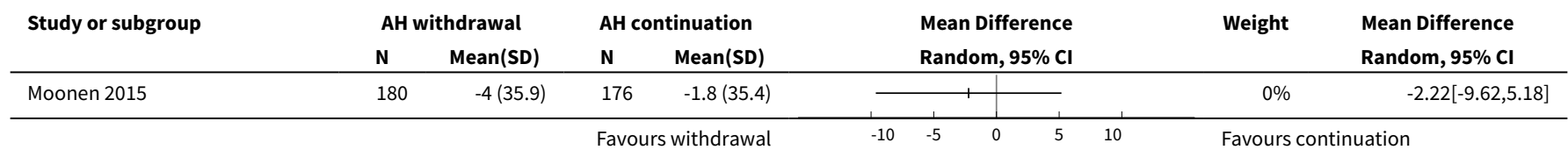

Analysis 2.4. Comparison 2 Change in cognitive function (over 16 weeks), Outcome 4 Trail making test score.

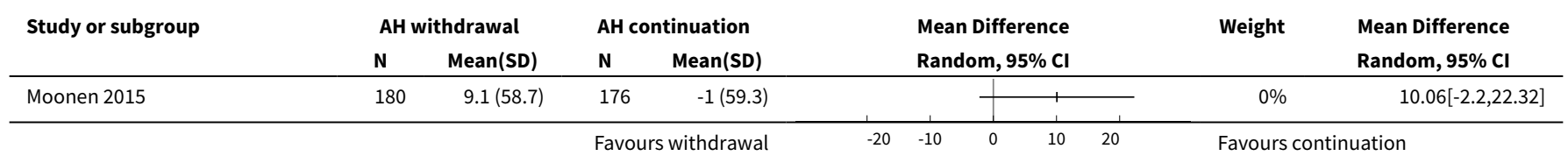

Analysis 2.5. Comparison 2 Change in cognitive function (over 16 weeks), Outcome 5 15-Word Verbal Learning Immediate Recall score.

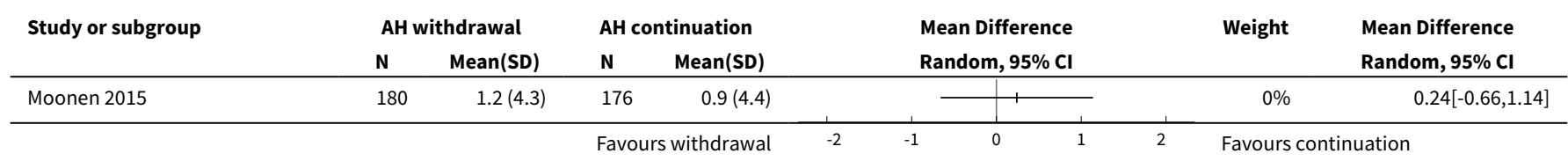


Analysis 2.6. Comparison 2 Change in cognitive function (over 16 weeks), Outcome 6 15-Word Verbal Learning Delayed Recall score.

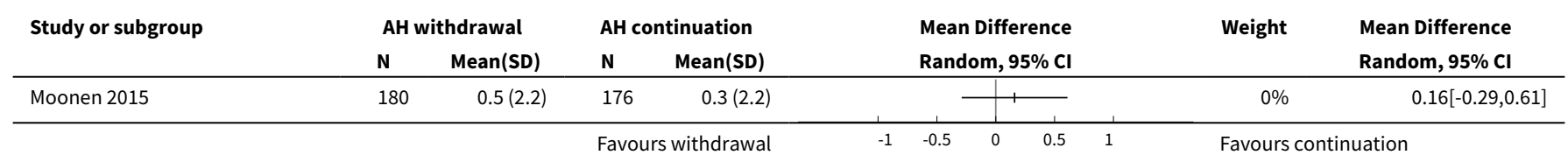

Analysis 2.7. Comparison 2 Change in cognitive function (over 16 weeks), Outcome 7 Visual Association Test score.

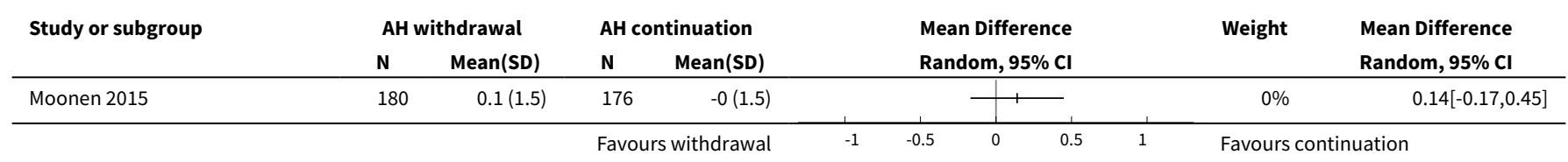

Comparison 3. Blood pressure (at 7 days)

\begin{tabular}{lllll}
\hline Outcome or subgroup title & No. of studies & $\begin{array}{l}\text { No. of partici- } \\
\text { pants }\end{array}$ & Statistical method & Effect size \\
\hline 1 Systolic blood pressure & 1 & Mean Difference (IV, Random, 95\% CI) & Subtotals only \\
\hline 2 Diastolic blood pressure & 1 & Mean Difference (IV, Random, 95\% CI) & Subtotals only \\
\hline
\end{tabular}

Analysis 3.1. Comparison 3 Blood pressure (at 7 days), Outcome 1 Systolic blood pressure.

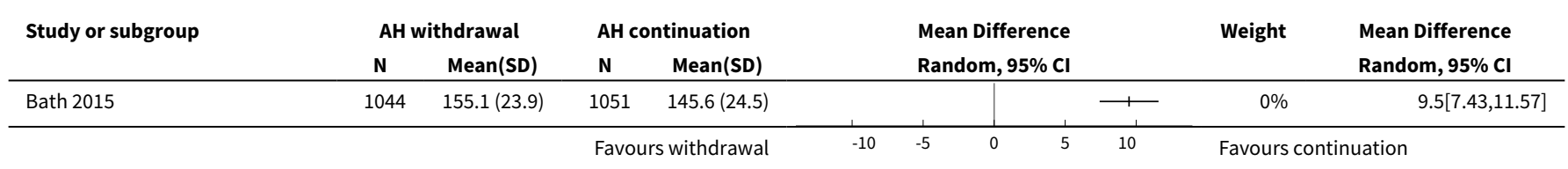

Analysis 3.2. Comparison 3 Blood pressure (at 7 days), Outcome 2 Diastolic blood pressure.

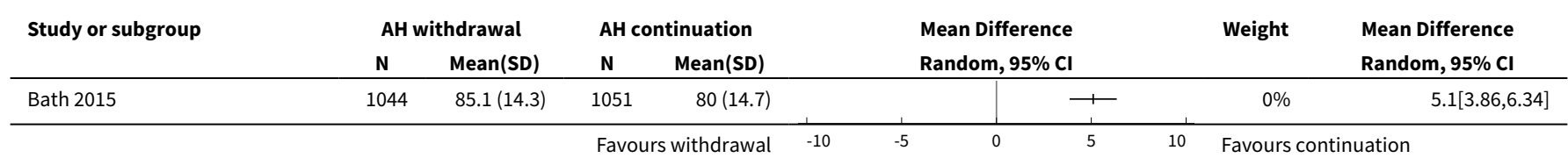


Comparison 4. Change in blood pressure (at 16 weeks)

\begin{tabular}{lllll}
\hline Outcome or subgroup title & No. of studies & $\begin{array}{l}\text { No. of partici- } \\
\text { pants }\end{array}$ & Statistical method & Effect size \\
\hline 1 Systolic blood pressure & 1 & Mean Difference (IV, Random, 95\% Cl) & Subtotals only \\
\hline 2 Diastolic blood pressure & 1 & Mean Difference (IV, Random, 95\% Cl) & Subtotals only \\
\hline
\end{tabular}

Analysis 4.1. Comparison 4 Change in blood pressure (at 16 weeks), Outcome 1 Systolic blood pressure.

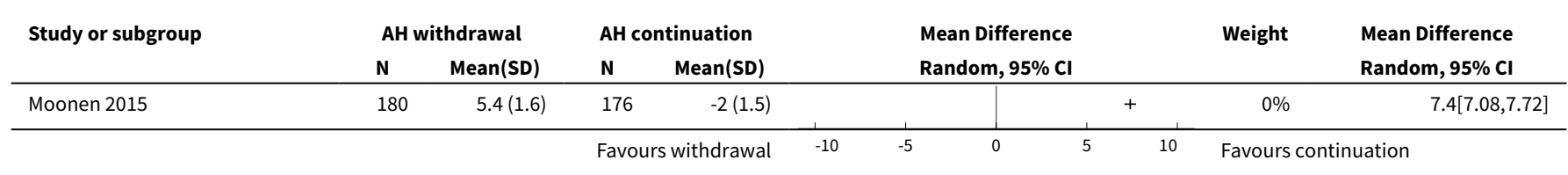

Analysis 4.2. Comparison 4 Change in blood pressure (at 16 weeks), Outcome 2 Diastolic blood pressure.

\begin{tabular}{|c|c|c|c|c|c|c|c|c|}
\hline \multirow{3}{*}{$\begin{array}{l}\text { Study or subgroup } \\
\text { Moonen } 2015\end{array}$} & \multicolumn{2}{|c|}{ AH withdrawal } & \multicolumn{2}{|c|}{ AH continuation } & \multirow{2}{*}{\multicolumn{2}{|c|}{$\begin{array}{l}\text { Mean Difference } \\
\text { Random, } 95 \% \mathrm{Cl}\end{array}$}} & \multirow[t]{2}{*}{ Weight } & \multirow{2}{*}{$\begin{array}{l}\text { Mean Difference } \\
\text { Random, } 95 \% \mathrm{Cl}\end{array}$} \\
\hline & $\mathbf{N}$ & Mean(SD) & $\mathbf{N}$ & Mean(SD) & & & & \\
\hline & 180 & $1.3(0.9)$ & 176 & $-1.3(0.8)$ & & + & $0 \%$ & $2.6[2.42,2.78]$ \\
\hline
\end{tabular}

\section{Comparison 5. Adverse events}

\begin{tabular}{llllll}
\hline Outcome or subgroup title & No. of studies & $\begin{array}{l}\text { No. of partici- } \\
\text { pants }\end{array}$ & Statistical method & Effect size \\
\hline 1 Mortality & 2 & 2485 & Risk Ratio (M-H, Random, 95\% Cl) & $0.88[0.72,1.08]$ \\
\hline 1.1 Mortality within 90 days & 1 & 2097 & Risk Ratio (M-H, Random, 95\% Cl) & $0.88[0.72,1.08]$ \\
\hline $\begin{array}{l}1.2 \text { Mortality within 16 weeks } \\
2 \text { Cardiovascular events }\end{array}$ & 1 & 388 & Risk Ratio (M-H, Random, 95\% Cl) & $0.95[0.06,15.08]$ \\
\hline $\begin{array}{l}2.1 \text { Any cardiovascular events } \\
\text { within 90 days }\end{array}$ & 1 & 2485 & Risk Ratio (M-H, Random, 95\% Cl) & $1.29[0.96,1.72]$ \\
\hline $\begin{array}{l}2.2 \text { Myocardial infarction with- } \\
\text { in 16 weeks }\end{array}$ & 1 & 2097 & Risk Ratio (M-H, Random, 95\% Cl) & $1.29[0.97,1.72]$ \\
\hline $\begin{array}{l}3 \text { Hospitalisation within 16 } \\
\text { weeks }\end{array}$ & 1 & 388 & Risk Ratio (M-H, Random, 95\% Cl) & $0.95[0.06,15.08]$ \\
\hline
\end{tabular}




\section{Analysis 5.1. Comparison 5 Adverse events, Outcome 1 Mortality.}

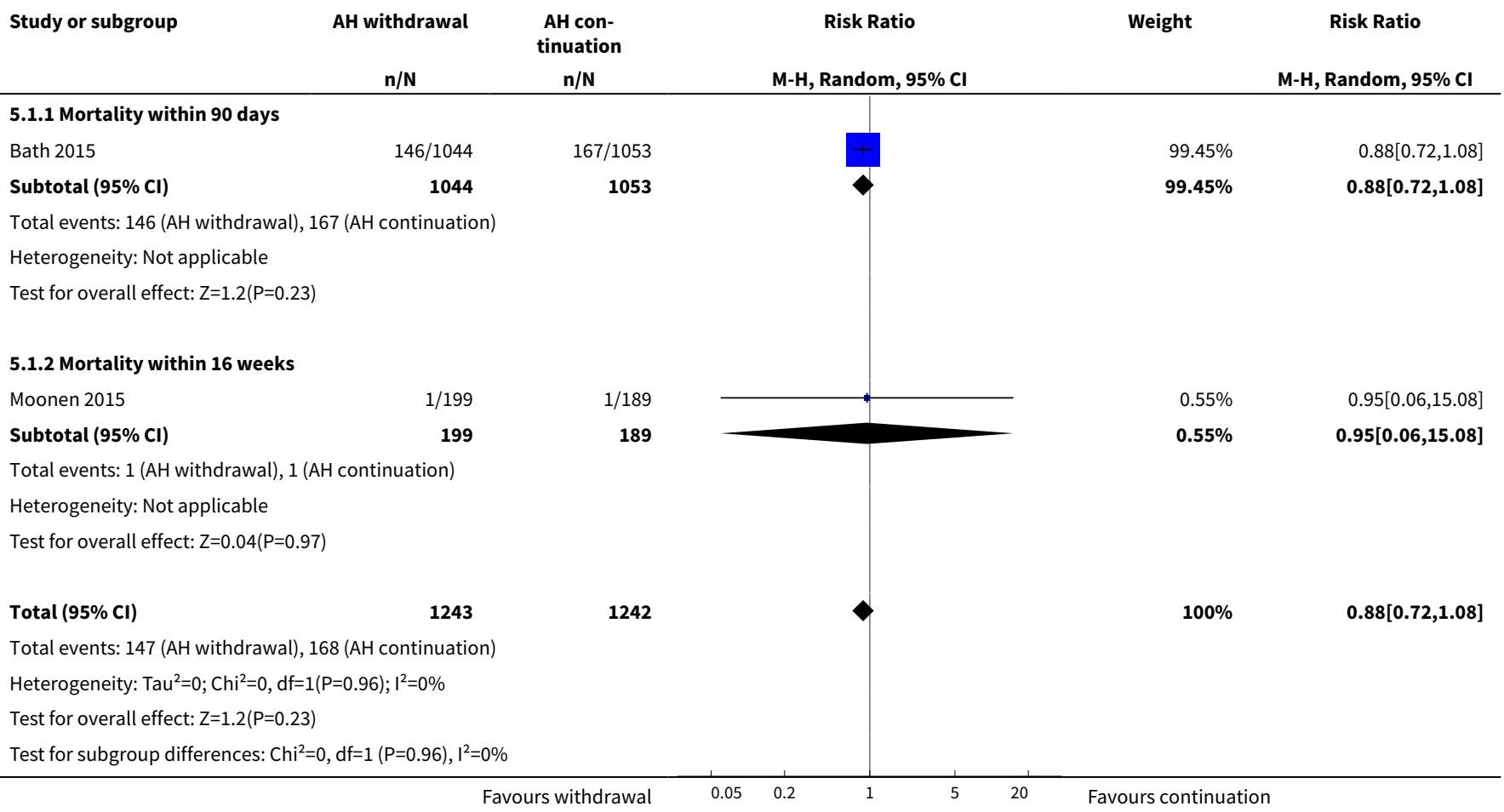

Analysis 5.2. Comparison 5 Adverse events, Outcome 2 Cardiovascular events.

Study or subgroup AH withdrawal AH conRisk Ratio Weight Risk Ratio $\mathrm{n} / \mathrm{N}$ M-H, Random, 95\% Cl M-H, Random, 95\% CI

\subsubsection{Any cardiovascular events within 90 days}

Bath 2015

96/1044

$75 / 1053$

Subtotal $(95 \% \mathrm{CI})$

1044

1053

$98.91 \%$

$1.29[0.97,1.72]$

Total events: 96 (AH withdrawal), 75 (AH continuation)

Heterogeneity: Not applicable

Test for overall effect: $Z=1.73(P=0.08)$

5.2.2 Myocardial infarction within 16 weeks

Moonen 2015

Total events: 1 (AH withdrawal), 1 (AH continuation)

Heterogeneity: Not applicable

Test for overall effect: $\mathrm{Z}=0.04(\mathrm{P}=0.97)$

$\begin{array}{llllllll}\text { Favours withdrawal } & 0.05 & 0.2 & 1 & 5 & 20 & \text { Favours continuation } & \end{array}$


Analysis 5.3. Comparison 5 Adverse events, Outcome 3 Hospitalisation within 16 weeks.

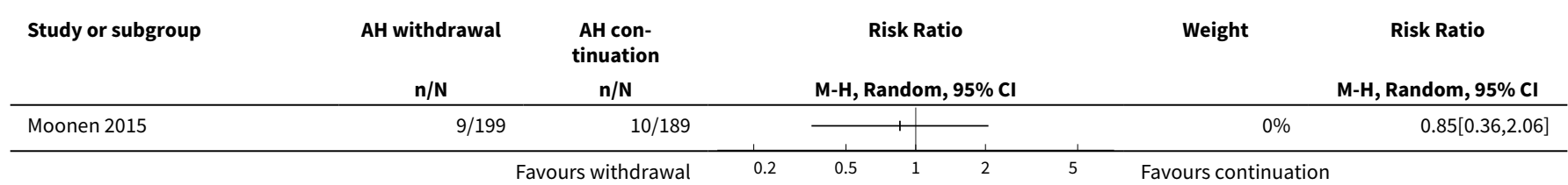

\section{Comparison 6. Adherence to withdrawal}

\begin{tabular}{lllll}
\hline Outcome or subgroup title & No. of studies & $\begin{array}{l}\text { No. of partici- } \\
\text { pants }\end{array}$ & Statistical method & Effect size \\
\hline 1 Adherence over all 7 days & 1 & 2095 & $\begin{array}{l}\text { Risk Ratio (M-H, Random, 95\% } \\
\text { Cl) }\end{array}$ & $1.34[1.26,1.42]$ \\
\hline
\end{tabular}

Analysis 6.1. Comparison 6 Adherence to withdrawal, Outcome 1 Adherence over all 7 days.

\begin{tabular}{|c|c|c|c|c|c|}
\hline \multirow[t]{2}{*}{ Study or subgroup } & \multirow{2}{*}{$\begin{array}{c}\text { AH withdrawal } \\
n / N \\
\end{array}$} & \multirow{2}{*}{$\begin{array}{c}\text { AH con- } \\
\text { tinuation } \\
n / N \\
\end{array}$} & \multirow{2}{*}{$\begin{array}{c}\text { Risk Ratio } \\
\text { M-H, Random, } 95 \% \mathrm{Cl}\end{array}$} & \multirow[t]{2}{*}{ Weight } & \multirow{2}{*}{$\begin{array}{c}\text { Risk Ratio } \\
\text { M-H, Random, 95\% Cl }\end{array}$} \\
\hline & & & & & \\
\hline Bath 2015 & $810 / 1044$ & $610 / 1051$ & & $100 \%$ & $1.34[1.26,1.42]$ \\
\hline Total $(95 \% \mathrm{Cl})$ & 1044 & 1051 & & $100 \%$ & $1.34[1.26,1.42]$ \\
\hline \multicolumn{6}{|c|}{ Total events: 810 (AH withdrawal), 610 (AH continuation) } \\
\hline Test for overall effect & & & & & \\
\hline
\end{tabular}

\section{ADDITIONAL TABLES}

Table 1. Baseline characteristics of participants and main interventions of included studies

\begin{tabular}{|c|c|c|c|c|c|}
\hline Study & $\begin{array}{l}\text { Number of ran- } \\
\text { domised partic- } \\
\text { ipants }\end{array}$ & $\begin{array}{l}\text { Type of antihyper- } \\
\text { tensive }\end{array}$ & $\begin{array}{l}\text { Mean age in } \\
\text { years (SD) }\end{array}$ & Male sex (\%) & Cognitive Outcomes \\
\hline Bath 2015 & $\begin{array}{l}\text { Total } 2097 \\
\text { IG } 1044 \\
\text { CG } 1053\end{array}$ & $\begin{array}{l}\text { No restrictions: any } \\
\text { previously prescribed } \\
\text { antihypertensive } \\
\text { treatment to be with- } \\
\text { drawn }\end{array}$ & $73(11)$ & $51 \%$ & $\begin{array}{l}\text { Assessed at 90-day follow-up: } \\
\text { - t-MMSE } \\
\text { - TICS-M }\end{array}$ \\
\hline Moonen 2015 & $\begin{array}{l}\text { Total } 393 \\
\text { IG } 199 \text { (180 in ITT } \\
\text { analysis) } \\
\text { CG } 186 \text { (176 in } \\
\text { ITT analysis) }\end{array}$ & $\begin{array}{l}\text { No restrictions: any } \\
\text { previously prescribed } \\
\text { antihypertensive } \\
\text { treatment to be with- } \\
\text { drawn }\end{array}$ & $\begin{array}{l}\text { IG: } 81.1(4.3) \\
\text { CG: } 81.5(4.6)\end{array}$ & $41 \%$ & $\begin{array}{l}\text { Assessed at baseline and } 16 \text {-week } \\
\text { follow-up; reported as change in } \\
\text { performance: } \\
\text { - Overall cognition (compound } \\
\text { score): Stroop Interference, } \\
\text { TMT, 15-WVLT Immediate Re- }\end{array}$ \\
\hline
\end{tabular}


Table 1. Baseline characteristics of participants and main interventions of included studies (Continued)

call, 15-WVLT Delayed Recall,
VAT and LDST
- MMSE
- SCWT
- TMT
- $15-$ WVLT
- VAT
- LDST

15-WVLT: 15-Word Verbal Learning Test; CG: control group; IG: intervention group; ITT: intention to treat; LDST: Letter-Digit Substitution Test; MMSE: Mini-Mental State Examination; SCWT: Stroop-Colour Word Test; TICS-M: Modified Telephone Interview for Cognitive Status; t-MMSE: telephone Mini-Mental State Examination; TMT: Trail Making Test; VAT: Visual Association Test.

\section{AP PE N D I CES}

\section{Appendix 1. All medications with antihypertensive function (irrespective of indication)}

Loop diuretics: bumetanide, ethacrynic acid, furosemide, torsemide

Thiazide diuretics: epitizide, hydrochlorothiazide and chlorothiazide, bendroflumethiazide, xipamide

Thiazide-like diuretics: indapamide, chlorthalidone, metolazone

Potassium-sparing diuretics: amiloride, triamterene

Dihydropyridines: amlodipine, cilnidipine, felodipine, isradipine, lercanidipine, levamlodipine, nicardipine, nifedipine, nimodipine, nitrendipine, barnidipine, lacidipine, aranidipine, azelnidipine, benidipine, clevidipine, darodipine, efonidipine, manidipine, niguldipine, nilvadipine, nisoldipine, nitrendipine, oxodipine, pranidipine

Non-dihydropyridines: diltiazem, verapamil

ACE-inhibitors: captopril, enalapril, fosinopril, lisinopril, perindopril, quinapril, ramipril, trandolapril, benazepril, zofenopril, imidapril, cilazapril

Angiotensin II receptor antagonists: candesartan, eprosartan, irbesartan, losartan, olmesartan, telmisartan, valsartan, azilsartan, fimasartan

Beta blockers: atenolol, metoprolol, nadolol, nebivolol, oxprenolol, pindolol, propranolol, timolol, bisoprolol, acebutolol, celiprolol, esmolol, sotalol

Alpha blockers: doxazosin, phentolamine, indoramin, phenoxybenzamine, prazosin, terazosin, tolazolin, ketanserin, urapidil, fentolamin

Mixed Alpha + Beta blockers: carvedilol, labetalol

Vasodilators: hydralazine, minoxidil

Renin Inhibitors: aliskiren

Aldosterone receptor antagonists: eplerenone, spironolactone

Alpha-2 adrenergic receptor agonists: clonidine, guanabenz, guanfacine, methyldopa, moxonidine, guanethidine, mecamylamine

Other: magnesium sulfate

Appendix 2. Search strategies

$\begin{array}{lll}\text { Source } & \text { Search strategy } & \text { Hits retrieved }\end{array}$


(Continued)

1. ALOIS (www.medicine.ox.ac.uk/alois)

[searched 12 December 2015]

2. MEDLINE In-process and other non-indexed citations and MEDLINE 1946-present (OvidSP)

[searched 12 December 2015]
1. (antihypertensive* or "anti-hypertensive ${ }^{\star}$ " or "angiotensin converting enzyme inhibitor" ${ }^{\star}$ or (angiotensin adj2 receptor antagonist*) or (angiotensin adj2 receptor block ${ }^{\star}$ ) or "AT 2 receptor block " or "AT 2 receptor antagon*" or ARB or ARBs or acei or ace-I or (ace adj2 inhibitor ${ }^{\star}$ ) or "adrenergic beta antagonist" " or "adrenergic alpha antagonist" or "beta block" or "alpha block" or diuretic* or "calcium channel blocker" or CCB or CCBs or chlorothiazide or chlorthalidone or hydralazine or hydrochlorothiazide or minoxidil or captopril or enalapril or fosinopril or lisinopril or ramipril or losartan or irbesartan or candesartan or eprosartan or valsartan or olmesartan or telmisartan or amlodipine or diltiazem or felodipine or nicardipine or nifedipine or nimodipine or verapamil or alprenolol or atenolol or metoprolol or nadolol or oxprenolol or pindolol or propranolol or labetalol or prazosin or spironolactone or triamterene or bumetanide or furosemide or indapamide or frusemide or diazoxide or eplerenone or amiloride or clonidine or methyldopa or isradipine or xipamide or barnidipine or lacidipine or aranidipine or azelnidipine or benidipine or clevidipine or darodipine or efonidipine or manidipine or niguldipine or nilvadipine or nisoldipine or nitrendipine or oxodipine or pranidipine or zofenopril or imidapril or cilazapril or azilsartan or fimasartan or bisoprolol or acebutolol or celiprolol or esmolol or sotalol or ketanserin or urapidil or fentolamin or minoxidil or "magnesium sulphate").ti,ab.

\section{2. exp Antihypertensive Agents/}

3. Hypertension/dt [Drug Therapy]

4. exp Angiotensin-Converting Enzyme Inhibitors/

5. exp Angiotensin Receptor Antagonists/

6. Angiotensin II/ai [Antagonists \& Inhibitors]

7. exp Adrenergic beta-Antagonists/

8. exp Adrenergic alpha-Antagonists/

9. exp Diuretics/

10. exp Calcium Channel Blockers/

11. Chlorothiazide/

12. Chlorthalidone/

13. Hydralazine/

14. Hydrochlorothiazide/

15. Minoxidil/

16. Captopril/

17. Enalapril/

18. Fosinopril/

19. Lisinopril/

20. Ramipril/ 


\section{Losartan/}

22. or/1-21

23. withdraw*.mp.

24. cessat* ${ }^{\star} \cdot \mathrm{mp}$.

25. (reduce $^{\star}$ or reducing ${ }^{\star}$ or reduct $\left.{ }^{\star}\right) . \mathrm{mp}$.

26. taper ${ }^{\star} . \mathrm{mp}$

27. stop ${ }^{\star} \cdot \mathrm{mp}$.

28. ("carr on" or continuation).mp.

29. ("come off" or "taken off").mp.

30. or/23-29

31.22 and 30

32. randomized controlled trial.pt.

33. controlled clinical trial.pt.

34. random* ${ }^{\star} \cdot a b$.

35. placebo.ab.

36. drug therapy.fs.

37. trial.ab.

38. groups.ab.

39. "double-blind*".ti,ab.

40. "single-blind".ti,ab.

41. or/32-40

42. 31 and 41

43. (cognition or cognitive).ti,ab.

44. (memory or "executive function*" or brain or mental).ti,ab.

45. Cognition/

46. Cognition Disorders/

47. Memory/

48. Delirium, Dementia, Amnestic, Cognitive Disorders/ or Dementia/

49. or/43-48

50.42 and 49

51. exp *Antihypertensive Agents/

52. exp *Hypertension/

53. (antihypertensive ${ }^{\star}$ or "anti-hypertensive ${ }^{\star " ~}$ or "angiotensin converting enzyme inhibitor ${ }^{\star}$ or (angiotensin adj2 receptor antagonist ${ }^{\star}$ ) or (angiotensin adj2 receptor block") or "AT 2 receptor block*" or "AT 2 receptor antagon*" or ARB or ARBs or acei or ace-I or (ace adj2 inhibitor ${ }^{\star}$ ) or "adrenergic beta antago- 
nist*" or "adrenergic alpha antagonist*" or "beta block*" or "alpha block*" or diuretic ${ }^{\star}$ or "calcium channel blocker*").ti,ab.

\section{4. or/51-53}

55. withdraw*.ti,ab.

56. 41 and 54 and 55

\subsection{0 or 56}

\section{EMBASE}

1974-2015 December 09 (OvidSP)

[searched 12 December 2015]
1. (antihypertensive* or "anti-hypertensive*" or "angiotensin converting enzyme inhibitor ${ }^{\star}$ " or (angiotensin adj2 receptor antagonist*) or (angiotensin adj2 receptor block $)$ or "AT 2 receptor block " or "AT 2 receptor antagon " or ARB or ARBs or acei or ace-I or (ace adj2 inhibitor ${ }^{\star}$ ) or "adrenergic beta antagonist*" or "adrenergic alpha antagonist*" or "beta block" " or "alpha block*" or diuretic* or "calcium channel blocker" or CCB or CCBs or chlorothiazide or chlorthalidone or hydralazine or hydrochlorothiazide or minoxidil or captopril or enalapril or fosinopril or lisinopril or ramipril or losartan or irbesartan or candesartan or eprosartan or valsartan or olmesartan or telmisartan or amlodipine or diltiazem or felodipine or nicardipine or nifedipine or nimodipine or verapamil or alprenolol or atenolol or metoprolol or nadolol or oxprenolol or pindolol or propranolol or labetalol or prazosin or spironolactone or triamterene or bumetanide or furosemide or indapamide or frusemide or diazoxide or eplerenone or amiloride or clonidine or methyldopa or isradipine or xipamide or barnidipine or lacidipine or aranidipine or azelnidipine or benidipine or clevidipine or darodipine or efonidipine or manidipine or niguldipine or nilvadipine or nisoldipine or nitrendipine or oxodipine or pranidipine or zofenopril or imidapril or cilazapril or azilsartan or fimasartan or bisoprolol or acebutolol or celiprolol or esmolol or sotalol or ketanserin or urapidil or fentolamin or minoxidil or "magnesium sulphate").ti,ab.

\section{2. antihypertensive agent/}

\section{3. hypertension/}

4. dipeptidyl carboxypeptidase inhibitor/

5. angiotensin receptor antagonist/

6. angiotensin II/

7. beta adrenergic receptor blocking agent/

8. alpha adrenergic receptor blocking agent/

9. diuretic agent/

10. calcium channel blocking agent/

11. chlorothiazide/

12. chlortalidone/

13. hydralazine/

14. hydrochlorothiazide/

15. minoxidil/

16. captopril/

17. enalapril/

18. fosinopril/ 

19. lisinopril/
20. ramipril/
21. losartan/
22. irbesartan/
23. or/1-22

24. treatment withdrawal/ or drug withdrawal/

25. withdraw*.ti,ab.

26. cessat*.ti,ab.

27. (reduce ${ }^{\star}$ or reducing ${ }^{\star}$ or reduct $^{\star}$ ).ti,ab.

28. taper ${ }^{\star}$. ti,ab.

29. stop*.ti,ab.

30. ("carr on" or continuation).ti,ab.

31. ("come off" or "taken off").ti,ab.

32. or/24-31

33. 23 and 32

34. (cognition or cognitive).ti,ab.

35. (memory or "executive function*" or brain or mental).ti,ab.

36. cognition/

37. dementia/

38. dement*.ti,ab

39. or/34-38

40. 33 and 39

41. randomized controlled trial/

42. controlled clinical trial/

43. random\$.ti,ab.

44. randomization/

45. intermethod comparison/

46. placebo.ti,ab.

47. (compare or compared or comparison).ti.

48. ((evaluated or evaluate or evaluating or assessed or assess) and (compare or compared or comparing or comparison)).ab.

49. (open adj label).ti,ab.

50. ((double or single or doubly or singly) adj (blind or blinded or blind-

ly)).ti,ab.

51. double blind procedure/ 
52. parallel group $\$ 1 . t i, a b$.

53. (crossover or cross over).ti,ab.

54. ((assign\$ or match or matched or allocation) adj5 (alternate or group $\$ 1$ or intervention $\$ 1$ or patient $\$ 1$ or subject $\$ 1$ or participant $\$ 1)$ ).ti,ab.

55. (assigned or allocated).ti,ab.

56. (controlled adj7 (study or design or trial)).ti,ab.

57. (volunteer or volunteers).ti,ab.

58. trial.ti.

59. or/41-58

60.40 and 59

\section{PSYCINFO}

1806-December week 2 2015 (OvidSP)

[searched 12 December 2015]

1. (antihypertensive* or "anti-hypertensive ${ }^{\star}$ " or "angiotensin converting enzyme inhibitor $^{\star}$ or (angiotensin adj2 receptor antagonist*) or (angiotensin adj2 receptor block ${ }^{\star}$ ) or "AT 2 receptor block " or "AT 2 receptor antagon*" or ARB or ARBs or acei or ace-I or (ace adj2 inhibitor ${ }^{\star}$ ) or "adrenergic beta antagonist*" or "adrenergic alpha antagonist*" or "beta block" or "alpha block*" or diuretic* or "calcium channel blocker" or CCB or CCBs or chlorothiazide or chlorthalidone or hydralazine or hydrochlorothiazide or minoxidil or captopril or enalapril or fosinopril or lisinopril or ramipril or losartan or irbesartan or candesartan or eprosartan or valsartan or olmesartan or telmisartan or amlodipine or diltiazem or felodipine or nicardipine or nifedipine or nimodipine or verapamil or alprenolol or atenolol or metoprolol or nadolol or oxprenolol or pindolol or propranolol or labetalol or prazosin or spironolactone or triamterene or bumetanide or furosemide or indapamide or frusemide or diazoxide or eplerenone or amiloride or clonidine or methyldopa or isradipine or xipamide or barnidipine or lacidipine or aranidipine or azelnidipine or benidipine or clevidipine or darodipine or efonidipine or manidipine or niguldipine or nilvadipine or nisoldipine or nitrendipine or oxodipine or pranidipine or zofenopril or imidapril or cilazapril or azilsartan or fimasartan or bisoprolol or acebutolol or celiprolol or esmolol or sotalol or ketanserin or urapidil or fentolamin or minoxidil or "magnesium sulphate").ti,ab.

\section{2. exp Hypertension/ or exp Antihypertensive Drugs/}

3. exp Adrenergic Drugs/

4. exp Diuretics/

5. exp Channel Blockers/

6. exp Hydralazine/

7. exp Captopril/

8. or/1-7

9. exp Drug Withdrawal/

10. withdraw*.ti,ab.

11. cessat $^{\star} \cdot \mathrm{ti}, \mathrm{ab}$.

12. (reduce ${ }^{\star}$ or reducing ${ }^{\star}$ or reduct $\left.{ }^{\star}\right) . t i, a b$.

13. taper $^{\star}$.ti,ab.

14. stop*.ti,ab. 
(Continued)
15. ("carr on" or continuation).ti,ab.
16. ("come off" or "taken off").ti,ab.
17. or/9-16
18. 8 and 17
19. exp Clinical Trials/
20. randomly.ab.
21. randomi?ed.ti,ab.
22. placebo.ti,ab.
23. groups.ab.
24. "double-blind"*tti,ab.
25. "single-blind*".ti,ab.
26. RCT.ti,ab.
27. or/19-26
28. 18 and 27

5. CINAHL (EBSCOhost)

[searched 12 December 2015]
S1 TX antihypertensive* OR "anti-hypertensive*" OR "angiotensin converting enzyme inhibitor*"

\section{S2 TX "AT 2 receptor block*" OR "AT 2 receptor antagon*" OR ARB OR ARBs OR} acei OR ace-I

S3 TX "adrenergic beta antagonist ${ }^{*}$ OR "adrenergic alpha antagonist*" OR "beta block*" OR "alpha block" OR diuretic* OR "calcium channel blocker" OR CCB OR CCBS

S4 TX chlorothiazide OR chlorthalidone OR hydralazine OR hydrochlorothiazide OR minoxidil OR captopril OR enalapril OR fosinopril OR lisinopril OR ramipril

S5 TX losartan OR irbesartan OR candesartan OR eprosartan OR valsartan OR olmesartan OR telmisartan OR amlodipine OR diltiazem OR felodipine OR nicardipine OR nifedipine OR nimodipine OR verapamil OR alprenolol OR atenolol OR metoprolol OR nadolol OR oxprenolol

S6 TX pindolol OR propranolol OR labetalol OR prazosin OR spironolactone OR triamterene OR bumetanide OR furosemide OR indapamide OR frusemide OR diazoxide OR eplerenone OR amiloride OR clonidine OR methyldopa OR isradipine OR xipamide OR barnidipine OR lacidipine OR aranidipine OR azelnidipine

S7 TX benidipine OR clevidipine OR darodipine OR efonidipine OR manidipine OR niguldipine OR nilvadipine OR nisoldipine OR nitrendipine OR oxodipine OR pranidipine OR zofenopril OR imidapril OR cilazapril OR azilsartan OR fimasartan OR bisoprolol OR acebutolol OR celiprolol OR esmolol OR sotalol OR ketanserin OR urapidil OR fentolamin OR minoxidil OR "magnesium sulphate"

S8 (MH "Hypertension")

S9 (MH "Diuretics")

S10 (MH "Angiotensin II Type I Receptor Blockers") OR (MH "Sodium Channel Blockers") OR (MH "Calcium Channel Blockers") 
(Continued)

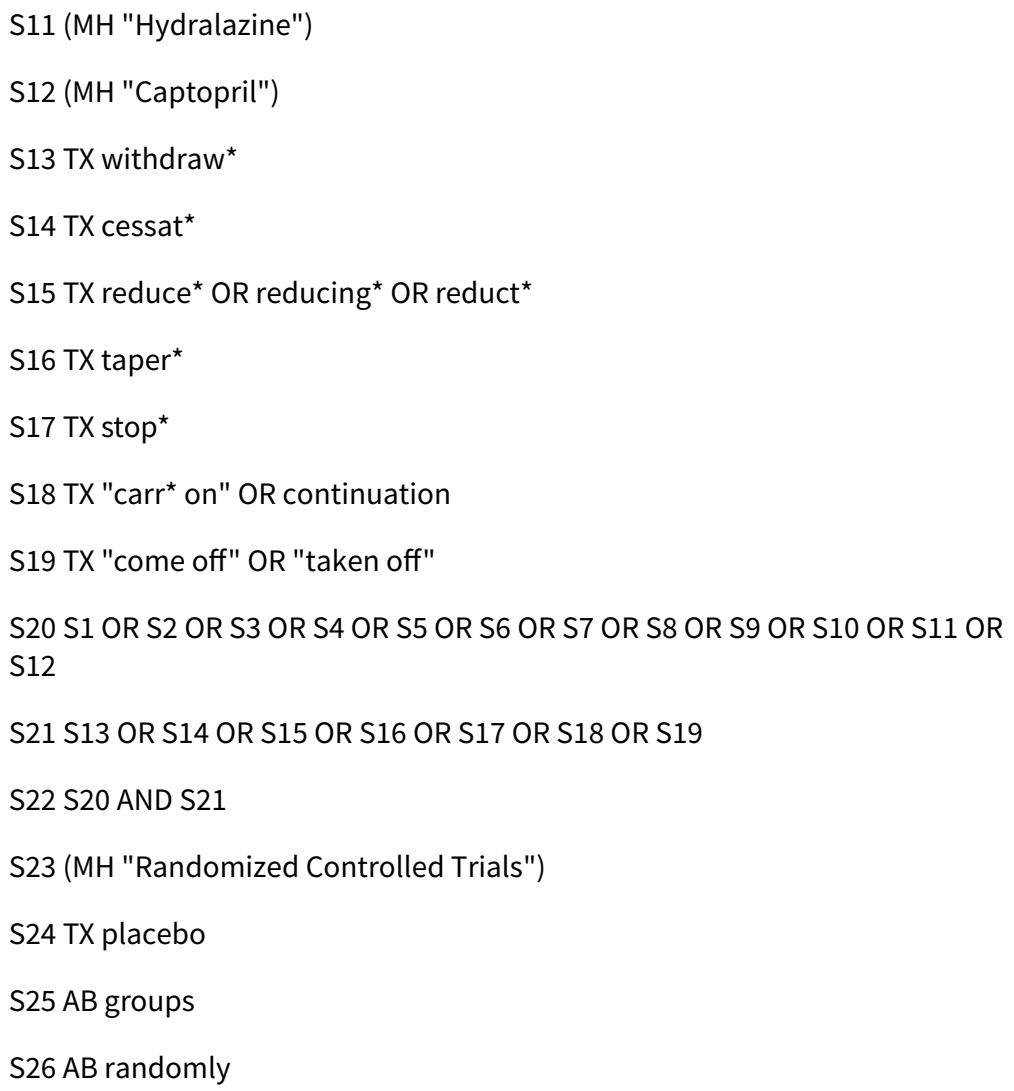

6. Web of Science core collection

[searched 12 December 2015]
TOPIC: (antihypertensive ${ }^{\star}$ or "anti-hypertensive ${ }^{\star}$ " or "angiotensin converting enzyme inhibitor*" or "AT 2 receptor block*" or "AT 2 receptor antagon*" or ARB or ARBs or acei or ace-I or "adrenergic beta antagonist ${ }^{\star}$ " or "adrenergic alpha antagonist" "calcium channel blocker*" OR CCB OR CCBs OR chlorothiazide OR chlorthali-
888

Antihypertensive withdrawal for the prevention of cognitive decline (Review)

Copyright $\odot 2016$ The Cochrane Collaboration. Published by John Wiley \& Sons, Ltd. 
done OR hydralazine OR hydrochlorothiazide OR minoxidil OR captopril OR enalapril OR fosinopril OR lisinopril OR ramipril OR losartan OR irbesartan OR candesartan OR eprosartan OR valsartan OR olmesartan OR telmisartan OR amlodipine OR diltiazem OR felodipine OR nicardipine OR nifedipine OR nimodipine OR verapamil OR alprenolol OR atenolol OR metoprolol OR nadolol OR oxprenolol OR pindolol OR propranolol OR labetalol OR prazosin OR spironolactone OR triamterene OR bumetanide OR furosemide OR indapamide OR frusemide OR diazoxide OR eplerenone OR amiloride OR clonidine OR methyldopa OR isradipine OR xipamide OR barnidipine OR lacidipine OR aranidipine OR azelnidipine OR benidipine OR clevidipine OR darodipine OR efonidipine OR manidipine OR niguldipine OR nilvadipine OR nisoldipine OR nitrendipine OR oxodipine OR pranidipine OR zofenopril OR imidapril OR cilazapril OR azilsartan OR fimasartan OR bisoprolol OR acebutolol OR celiprolol OR esmolol OR sotalol OR ketanserin OR urapidil OR fentolamin OR minoxidil OR "magnesium sulphate") AND TOPIC: (withdraw* or reduce or stop* or taper* or cessat* or reduction) AND TOPIC: (cognition or cognitive or "executive function ${ }^{\star}$ " or memory or dementia or alzheimer ${ }^{\star}$ ) AND TOPIC: (random ${ }^{\star}$ or trial or placebo or "double-blind*" or "single-blind*" or RCT or "control group*")

Timespan: All years.

Search language=Auto

\section{LILACS (BIREME)}

[searched 12 December 2015] "angiotensin converting enzyme inhibitor\$" OR antihypertensive OR antihypertensives [Words] and dementia OR demencia OR demência OR alzheimer OR alzheimers OR alzheimer's OR cognition [Words]

\section{CENTRAL (the Cochrane Library) (Is- sue 1 of 4,2015)}

[searched 12 December 2015] \#1antihypertensive* or "anti-hypertensive*" or "angiotensin converting enzyme inhibitor" or "AT 2 receptor block*" or "AT 2 receptor antagon*" or ARB or ARBs or acei or ace-I or "adrenergic beta antagonist " or "adrenergic alpha antagonist" " or "beta block*" or "alpha block*" or diuretic* or "calcium channel blocker*" or CCB or CCBs or chlorothiazide or chlorthalidone or hydralazine or hydrochlorothiazide or minoxidil or captopril or enalapril or fosinopril or lisinopril or ramipril or losartan or irbesartan or candesartan or eprosartan or valsartan or olmesartan or telmisartan or amlodipine or diltiazem or felodipine or nicardipine or nifedipine or nimodipine or verapamil or alprenolol or atenolol or metoprolol or nadolol \#2metoprolol or nadolol or oxprenolol or pindolol or propranolol or labetalol or prazosin or spironolactone or triamterene or bumetanide or furosemide or indapamide or frusemide or diazoxide or eplerenone or amiloride or clonidine or methyldopa or isradipine or xipamide or barnidipine or lacidipine or aranidipine or azelnidipine or benidipine or clevidipine or darodipine or efonidipine or manidipine or niguldipine or nilvadipine or nisoldipine or nitrendipine or oxodipine or pranidipine or zofenopril or imidapril or cilazapril or azilsartan or fimasartan or bisoprolol or acebutolol or celiprolol or esmolol or sotalol or ketanserin

\#3urapidil or fentolamin or minoxidil or "magnesium sulphate" \#4MeSH descriptor: [Antihypertensive Agents] explode all trees \#5MeSH descriptor: [Hypertension] explode all trees \#6\#1 or \#2 or \#3 or \#4 or \#5 $\# 7$ reduc ${ }^{\star}$ or stop* or taper $^{\star}$ or cessat* or withdraw* \#8\#6 and \#7 \#9cognit* \#10dement* \#11MeSH descriptor: [Cognition] explode all trees \#12MeSH descriptor: [Dementia] explode all trees \#13memory \#14"executive function*" $\# 15 \# 9$ or \#10 or \#11 or \#12 or \#13 or \#14 
9. Clinicaltrials.gov

(www.clinicaltrials.gov)

[searched 12 December 2015]

\section{ICTRP Search Por- tal (apps.who.int/tri- alsearch) [includes: Australian New Zealand Clinical Trials Reg- istry; ClinicalTrilas.gov; ISRCTN; Chinese Clini- cal Trial Registry; Clini- cal Trials Registry - In- dia; Clinical Research Information Service - Republic of Korea; Ger- man Clinical Trials Reg- ister; Iranian Registry of Clinical Trials; Japan Primary Registries Net- work; Pan African Clin- ical Trial Registry; Sri Lanka Clinical Trials Registry; The Nether- lands National Trial Register]}

[searched 12 December 2015]
Interventional studies:

("angiotensin converting enzyme inhibitor" OR antihypertensive OR antihypertensives) AND (cognition OR cognitive OR dementia)

Recruitment status: ALL

("angiotensin converting enzyme inhibitor" OR antihypertensive OR antihyper- 4 tensives) AND (cognition OR cognitive OR dementia)

Recruitment status: ALL

\section{CONTRIBUTIONS OF AUTHORS}

SJ and JH conducted study selection, data extraction, data analysis and produced an initial draft of the review, amended in accordance with TQ and ER's comments.

ER assisted in resolving any conflicts in study selection.

TQ and ER provided supervision and support to SJ and JH, revising the review drafts in preparation for submission.

\section{DECLARATIONS OF INTEREST}

SJ has no known conflicts of interest.

JH was a named co-applicant on a UK National Institute for Health Research (NIHR) grant conducting a feasibility study of antihypertensive withdrawal for people with dementia, jointly run by the University of Nottingham and the University of Leicester.

TQ has no known conflicts of interest.

ER has no known conflicts of interest. 


\section{SOURCES OF SUPPORT}

\section{Internal sources}

- Academic Medical Center, University of Amsterdam, Netherlands.

- Institute of Cardiovascular and Medical Sciences, University of Glasgow, UK.

- Centre for Cognitive Ageing and Cognitive Epidemiology and The Alzheimer Scotland Dementia Research Centre, University of Edinburgh, UK.

- Alzheimer Scotland and The University of Edinburgh Centre for Cognitive Ageing and Cognitive Epidemiology, UK.

JKH is supported by a Clinical Research Fellowship funded by Alzheimer Scotland and The University of Edinburgh Centre for Cognitive Ageing and Cognitive Epidemiology, part of the cross council Lifelong Health and Wellbeing Initiative (MR/L501530/1). Funding from the Biotechnology and Biological Sciences Research Council (BBSRC) and Medical Research Council (MRC) is gratefully acknowledged.

- Stroke Association, UK.

TQ is supported by a joint Stroke Association, Chief Scientist Office Senior Clinical Lectureship

\section{External sources}

- NIHR, UK.

This review was supported by the National Institute for Health Research (NIHR), via a Cochrane Programme Grant to the Cochrane Dementia and Cognitive Improvement group. The views and opinions expressed therein are those of the authors and do not necessarily reflect those of the Systematic Reviews Programme, NIHR, National Health Service or the Department of Health

\section{DIFFERENCES BETWEEN PROTOCOL AND REVIEW}

In the protocol, there was inconsistency in the description of the outcomes reported in 'Secondary outcomes' and those to be reported in our 'Summary of findings' tables. We incorrectly stated we would look at recommencement of antihypertensive medications in our 'Summary of findings' table, when the outcome we intended to present in the table was adherence to withdrawal. This has been amended.

In the protocol, we prespecified nine outcome measures for inclusion in the 'Summary of findings' table. In accordance with Cochrane guidance and following review by the Cochrane Dementia and Cognitive Improvement Group editorial team, we did not present change in systolic and diastolic blood pressure and adherence to withdrawal in the table.

Due to a lack of data, we could not perform a meta-analysis on all outcomes we described in the protocol. In the protocol, we described several sensitivity analyses, but these could not be performed with the two studies we included.

\section{INDEX TERMS}

\section{Medical Subject Headings (MeSH)}

*Antihypertensive Agents; *Withholding Treatment; Blood Pressure [physiology]; Cognition [drug effects]; Cognitive Dysfunction [ ${ }^{\star}$ prevention \& control]; Dementia [prevention \& control]; Randomized Controlled Trials as Topic; Stroke; Time Factors

\section{MeSH check words}

Adult; Humans 